Article

\title{
Cross-Border Investigations on the Prevalence and Transmission Dynamics of Cryptosporidium Species in Dairy Cattle Farms in Western Mainland Europe
}

\author{
Pedro Pinto ${ }^{1}$, Cláudia A. Ribeiro ${ }^{1}$, Sumaiya Hoque ${ }^{1}\left(\mathbb{D}\right.$, Ourida Hammouma ${ }^{2}$, Hélène Leruste ${ }^{3}$, \\ Sébastien Détriché ${ }^{4}\left(\mathbb{D}\right.$, Evi Canniere ${ }^{5}{ }^{\circledR}$, Yvonne Daandels ${ }^{6}$, Martine Dellevoet ${ }^{6}$, Janine Roemen ${ }^{6}$, \\ Anne Barbier Bourgeois ${ }^{7}$, Martin Kváč ${ }^{8,9}$, Jérôme Follet ${ }^{10}$ and Anastasios D. Tsaousis ${ }^{1, *(1)}$
}

check for

updates

Citation: Pinto, P.; Ribeiro, C.A.;

Hoque, S.; Hammouma, O.; Leruste,

H.; Détriché, S.; Canniere, E.;

Daandels, Y.; Dellevoet, M.; Roemen,

J.; et al. Cross-Border Investigations

on the Prevalence and Transmission

Dynamics of Cryptosporidium Species

in Dairy Cattle Farms in Western

Mainland Europe. Microorganisms

2021, 9, 2394. https://doi.org/

10.3390/microorganisms 9112394

Academic Editor: Gereon R.

M. Schares

Received: 15 October 2021

Accepted: 15 November 2021

Published: 20 November 2021

Publisher's Note: MDPI stays neutral with regard to jurisdictional claims in published maps and institutional affiliations.

Copyright: (c) 2021 by the authors. Licensee MDPI, Basel, Switzerland. This article is an open access article distributed under the terms and conditions of the Creative Commons Attribution (CC BY) license (https:/ / creativecommons.org/licenses/by/ $4.0 /)$.
1 Laboratory of Molecular and Evolutionary Parasitology, RAPID Group, School of Biosciences, University of Kent, Canterbury CT2 7NZ, UK; pp410@kent.ac.uk (P.P.); C.Azevedo-Ribeiro@kent.ac.uk (C.A.R.); sh986@kent.ac.uk (S.H.)

2 UMR-Transfrontalière 1158 BioEcoAgro, Junia, University of Lille, University of Liège, UPJV, ULCO, University of Artois, INRAE, F-59000 Lille, France; ourida.hammouma@junia.com

3 Junia, Comportement Animal et Systèmes d'Elevage, F-59000 Lille, France; helene.leruste@junia.com

4 University of Lille, Institut Mines-Télécom, University of Artois, Junia, ULR 4515-LGCgE, Laboratoire de Génie Civil et Géo-Environnement, F-59000 Lille, France; sebastien.detriche@junia.com

5 Inagro vzw, Ieperseweg 87, 8800 Rumbeke-Beitem, Belgium; evi.canniere@inagro.be

6 Southern Agricultural and Horticultural Organisation (ZLTO), Onderwijsboulevard 225, 5223 DE's-Hertogenbosch, The Netherlands; yvonne.daandels@zlto.nl (Y.D.); martine.dellevoet@zlto.nl (M.D.); janine@agrisyst.com (J.R.)

7 Selas, 31 Rue de la République, 59496 Salome, France; anne.barbier@selascve.fr

8 Biology Centre of the Academy of Sciences of the Czech Republic, Institute of Parasitology, 37005 České Budějovice, Czech Republic; kvac@paru.cas.cz

9 Faculty of Agriculture, University of South Bohemia in České Budějovice, 37005 České Budějovice, Czech Republic

10 University of Lille, CNRS, Centrale Lille, Junia, University Polytechnique Hauts de France, UMR 8520 IEMN Institut d'Electronique de Microélectronique et de Nanotechnologie, F 59000 Lille, France; jerome.follet@junia.com

* Correspondence: A.Tsaousis@kent.ac.uk or tsaousis.anastasios@gmail.com; Tel.: +44-1227-827-007

\begin{abstract}
Cryptosporidium is an apicomplexan parasitic protist, which infects a wide range of hosts, causing cryptosporidiosis disease. In farms, the incidence of this disease is high in animals such as cows, leading to extensive economic loss in the livestock industry. Infected cows may also act as a major reservoir of Cryptosporidium spp., in particular C. parvum, the most common cause of cryptosporidiosis in these animals. This poses a risk to the trading of livestock, to other farms via breeding centres, and to human health. This study is a part of a global project aimed at strategies to tackle cryptosporidiosis. To reach this target, it was essential to determine whether prevalence was dependent on the studied countries or if the issue was borderless. Indeed, C. parvum occurrence was assessed across dairy farms in certain regions of Belgium, France, and the Netherlands. At the same time, the animal-to-animal transmission of the circulating C. parvum subtypes was studied. To accomplish this, we analysed 1084 faecal samples, corresponding to 57 dairy farms from all three countries. To this end, $18 S$ rRNA and $g p 60$ genes fragments were amplified, followed by DNA sequencing, which was subsequently used for detection and subtyping C. parvum. Bioinformatic and phylogenetic methods were integrated to analyse and characterise the obtained DNA sequences. Our results show 25.7\%, 24.9\% and 20.8\% prevalence of Cryptosporidium spp. in Belgium, France, and the Netherlands respectively. Overall, $93 \%$ of the farms were Cryptosporidium positive. The gp60 subtyping demonstrated a significant number of the C. parvum positives belonged to the IIa allelic family, which has been also identified in humans. Therefore, this study highlights how prevalent C. parvum is in dairy farms and further suggests cattle as a possible carrier of zoonotic C. parvum subtypes, which could pose a threat to human health.
\end{abstract}


Keywords: $18 S$ rRNA; Cryptosporidium; dairy cattle; gp60; genotyping; prevalence

\section{Introduction}

Cryptosporidium is a genus of enteric apicomplexan parasites, responsible for causing cryptosporidiosis in a diverse range of vertebrate hosts, including livestock and humans $[1,2]$. Cryptosporidiosis is one of the prominent causes of diarrheal illness in humans and animals worldwide, with children, newborn animals and immunocompromised individuals being especially vulnerable to the disease [3-5]. Cryptosporidium infections occur after ingestion of oocysts through the fecal-oral route, either directly after contact with animals infected or incidentally through contaminated material such as food, water, soil and fomites [6,7]. Thus, a One-Health approach, where all these factors are considered, is essential to investigate the role and transmission dynamics of this parasite in both humans and other animals [7].

In livestock, cryptosporidiosis primarily manifests as a gastrointestinal disease, causing watery diarrhea, malnutrition, abdominal pain, dehydration and, in severe cases, death $[7,8]$. This disease is deemed globally endemic in cattle and it is particularly prevalent in neonatal and pre-weaned calves ( $<6$ weeks old), in which it is one of the most common causes of diarrheic illness $[9,10]$. Cryptosporidium infection and consequent disease appear in both beef and dairy calves, with higher prevalence in intensive livestock management systems [11]. Clinical manifestations of cryptosporidiosis in calves lead to long term impacts on their well-being and consequently, the disease puts a considerable economic burden on the cattle industry $[9,10,12]$. Costs associated with the economic burden of the disease include seeking veterinary expertise for diagnosis and medication, along with additional costs linked to animal rearing and supplemental nutrition to regain meat and milk yield. An additional cost of purchasing new animals has to be incurred in case of death [13]. In the United Kingdom, the extra cost to manage diarrheal diseases, including Cryptosporidium, has been estimated at an average of GBP 32 per calf with an annual total spending of GBP 11 million [13,14]. More recently, the economic burden of cryptosporidiosis in calves was highlighted, with projections reaching GBP 100-200 per Cryptosporidium-infected calf. The long-term difference in the growth of beef calves with and without cryptosporidiosis was also assessed $[10,15]$. An average variation of $34 \mathrm{~kg}$ was observed between the two groups, with infected calves being considerably lighter than the uninfected, translating into a profit deficit of approximately GBP 128 per animal according to market prices in 2018 [10]. Hence, studying the prevalence and transmission dynamics of this parasite in cattle farming is crucial.

Cryptosporidium spp. incidence in cattle is mostly attributed to four species: C. andersoni, C. bovis, C. parvum, and C. ryanae [3]. Remarkably, an age-related scattering pattern has been noted, with $C$. bovis and $C$. ryanae being prevalent in post-weaned calves, while $C$. andersoni being the main infective species in adults [13,16-22]. The latter three species have non or low pathogenic potential and seem to be host-adapted [23-25]. In contrast, C. parvum is the main source of infection in pre-weaned calves and the only species associated with typical cryptosporidiosis symptoms in cattle $[7,17,19,26,27]$. Most notably, C. parvum is capable of infecting multiple animal hosts and is the primary zoonotic agent of cryptosporidiosis $[5,28]$. Hence, it is of particular concern that, during the infective stage, calves can shed an extraordinary number of oocysts in their feces (roughly $10 \times 10^{10}$, per day) [29]. Since oocysts are extraordinarily resistant to a vast array of conditions, including common disinfectants, they can persist in the environment for long periods, and become readily infective after ingestion by humans and other animals [30-32]. 
To truly uncover the species diversity, zoonotic potential, and transmission dynamics of the different Cryptosporidium spp. circulating in cattle, molecular tools must be employed. By targeting and amplifying the $18 \mathrm{~S}$ ribosomal RNA gene followed by sequencing, it is possible to accurately distinguish and characterize Cryptosporidium at the species level $[2,33]$. Subsequently, amplification of the $60 \mathrm{kDa}$ glycoprotein gene $(g p 60)$ can be used to explore the intraspecific diversity of C. paroum in order to categorize it into different subtype families and further differentiate subtypes within the same family $[2,33,34]$. These molecular tools have been extensively employed to assess $C$. parvum's role in zoonotic transmission and to trace sources of cryptosporidiosis outbreaks [6,35]. Cryptosporidium spp. prevalence studies with further molecular characterization in cattle farms across Belgium, France and the Netherlands are quite sparse. Several reports have documented Cryptosporidium spp. occurrence and description of zoonotic species/subtypes in dairy or beef calves employing molecular tools in France [36-42]. To our knowledge, only one such study has been conducted in Belgium [43] and the Netherlands [44]. Therefore, the aim of the present study was to provide up-to-date information regarding the prevalence and transmission dynamics of Cryptosporidium species in cattle farms on a wide geographic area across Belgium, France, and the Netherlands, while subsequently investigating potential circulation of subtypes within and between farms and even countries.

\section{Material and Methods}

\subsection{Geographical Area of Research and Study Model}

This study was conducted under the Health for Dairy Cows (H4DC) project, funded by the Interreg 2 seas programme (https:/ /h4dc-interreg2seas.eu/; accessed on 20 November 2021). This is a European territorial cooperation program covering the regions along the Southern North Sea and the Channel. This includes certain districts, such as the Flanders region of Belgium, the south of England, the Hautes-de-France region in France, and the west part of the Netherlands. The main objective of the project is to reduce the sanitary and economic impact of Cryptosporidium spp. on farms.

\subsection{Faecal Sample Collection}

Faecal sample collection for all participating farms in this study occurred between September 2019 and June 2020. Fifty-seven farms were surveyed from three countries: Belgium, France and the Netherlands (Figure 1). The partners of the project selected the participating farms. Most farmers participated in this study because of one of the following reasons: (1) the dairy cows in their farms were encountering issues with diarrhoea; (2) they were willing to participate in the study regardless; and/or (3) they were willing to potentially change their farming practices. On each farm, veterinarians were instructed to collect 10 individual faecal samples, preferentially from the youngest calves up to three months of age and 10 individual faecal samples from their respective mothers, directly from the rectum and regardless of their clinical condition (diarrhoeic or non-diarrhoeic). Thus, on average, a total of 20 samples were collected per farm. For farms with less than 10 calves $\leq 3$ months old, fewer samples of calves (and their mothers) were collected. All participating farms were visited once. In one of the farms in Belgium, a total of 41 samples were collected ( 20 calves and 21 adults). Each sample was gathered using a single pair of disposable gloves, transferred to a $40 \mathrm{~mL}$ faecal collection container, and stored in a portable cooler until arriving to the storage place. Samples were stored at $-20^{\circ} \mathrm{C}$ until finally shipped on ice packs to the laboratories for further analysis. All samples contained the animal identification number, the relationship status between calf and mother, as well as, the date of sampling, age of the animal, farm identification and country of origin. 


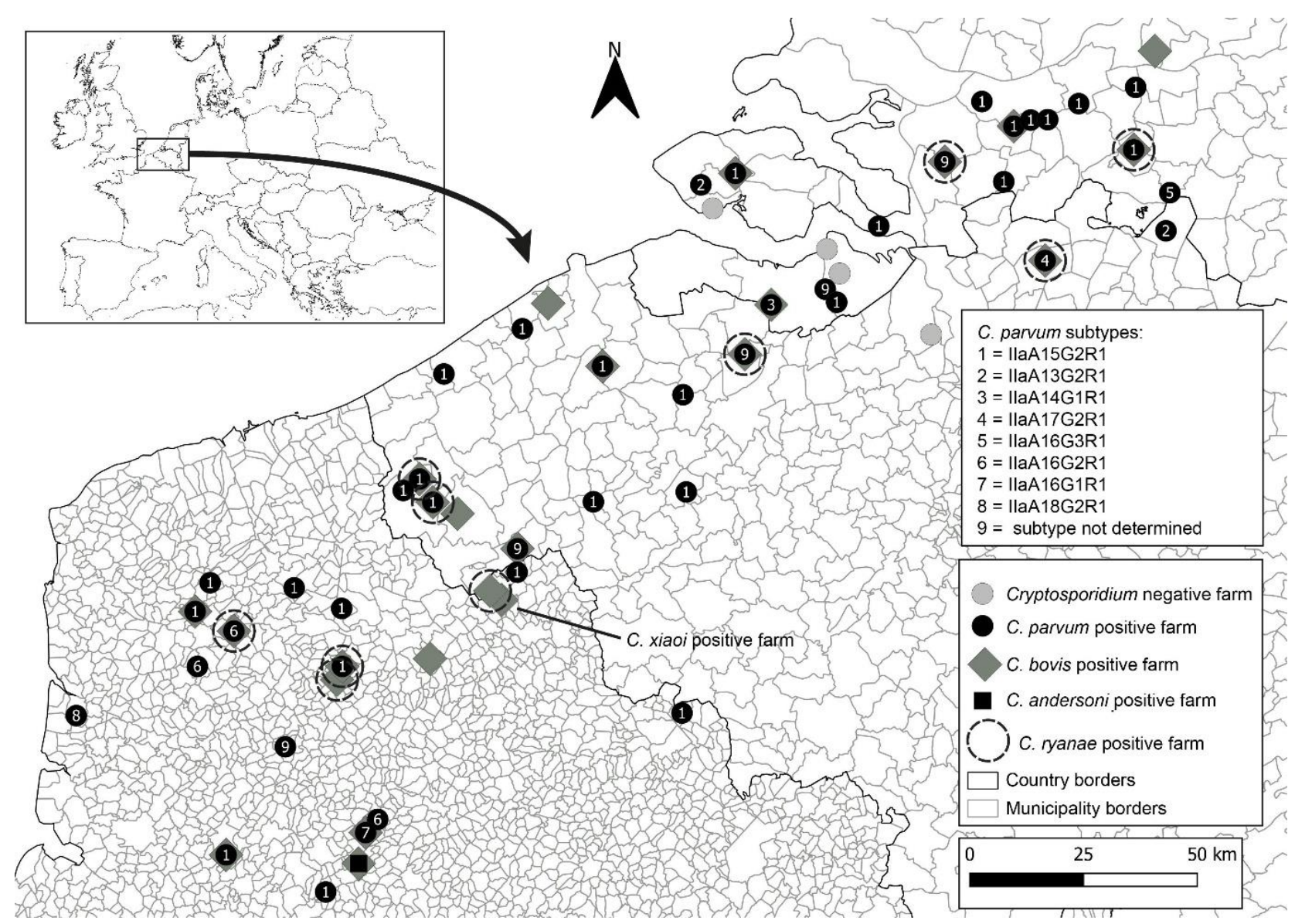

Figure 1. Geographical map of Belgium, France and the Netherlands indicating farms negative for Cryptosporidium spp. (grey circles) and farms positive for C. parvum (black circles), C. bovis (grey diamonds), and C. andersoni (black square). Distribution of $C$. parvum isolates with gp60 subtypes are represented as numbers.

\subsection{Sample Processing and DNA Extraction}

Frozen faecal samples were thawed overnight at $4{ }^{\circ} \mathrm{C}$ and approximately $200 \mathrm{mg}$ of faecal material was used to extract genomic DNA (gDNA) with the PureLink ${ }^{\mathrm{TM}}$ Microbiome DNA Purification Kit (Thermo Fisher Scientific, Carlsbad, CA, USA), according to the manufacturer's commercial protocols with slight modifications. After the addition of clean-up buffer and instant vortex, samples were left to incubate at the fridge for $10 \mathrm{~min}$ to improve the removal of PCR inhibitors. DNA was then recovered with elution buffer and stored at $-20^{\circ} \mathrm{C}$ until further analysis.

\subsection{Cryptosporidium spp. Detection, and Subtyping}

Cryptosporidium spp. detection was attained through a nested PCR reaction amplification of the $18 \mathrm{~S}$ rRNA gene sequence. The primary reaction was conducted using the primers CRY_SSU_F1 5' ${ }^{\prime}$-GATTAAGCCATGCATGTCTAA-3' and CRY_SSU_R1 $5^{\prime}$-TTCCATGCTGGAGTATTCAAG-3' (product size: $723 \mathrm{bp}$ ) and the secondary reaction of the nested PCR was conducted using the forward primer CRY_SSU_F2 $5^{\prime}$-CAGTTATAGTTTACTTGATAATC- $3^{\prime}$ and the reverse primer CRY_SSU_R2 5'-CCTGCTTTAAGCACTCTAATTTTC-3' (product size $\sim 631 \mathrm{bp}$ ) [45]. The primary PCR mixture was performed in a $25 \mu \mathrm{L}$ volume containing $1 \mu \mathrm{L}$ of template gDNA (concentration $10-100 \mathrm{ng} / \mu \mathrm{L}$ ), $0.4 \mu \mathrm{M}$ of each primer, $12.5 \mu \mathrm{L}$ of $2 \times$ PCRBIO Taq Mix Red (PCR Biosystems, London, UK). All amplifications were performed in a C1000 Touch PCR thermal cycler (Bio-Rad Laboratories, Inc., Berkeley, CA, USA) with an initial denaturation at $94{ }^{\circ} \mathrm{C}$ for $2 \mathrm{~min}$, followed by 24 cycles of denaturation at $94{ }^{\circ} \mathrm{C}$ for $50 \mathrm{~s}$, annealing at $53{ }^{\circ} \mathrm{C}$ for $50 \mathrm{~s}$, and extension at $72{ }^{\circ} \mathrm{C}$ for $1 \mathrm{~min}$. Lastly, a final 
extension step at $72{ }^{\circ} \mathrm{C}$ for $10 \mathrm{~min}$ was also included. For the second PCR reaction, $1 \mu \mathrm{L}$ of the PCR product obtained from the first PCR reaction was used as a template, and the remaining of the mixture was prepared as described above for the primary reaction. The cycling conditions for the second PCR reaction differed on the number of cycles, with 30 cycles instead of 24 , and the annealing conditions, with $56{ }^{\circ} \mathrm{C}$ for $30 \mathrm{~s}$ being used instead. Amplification of the gp60 by nested PCR was carried out using the primers AL3531 5' -ATAGTCTCCGCTGTATTC-3' and AL3535 5'-GGAAGGAACGATGTATCT- 3' (product size: $1000 \mathrm{bp}$ ) in the primary reaction of the nested PCR, and the primers AL3532 5'-TCCGCTGTATTCTCAGCC-3' and AL3534 5'-GCAGAGGAACCAGCATC-3' ( $850 \mathrm{bp})$ in the secondary reaction of the nested PCR [46]. Briefly, the primary and secondary PCR mixtures contained $2 \mu \mathrm{L}$ of gDNA (ranging from 10 to $100 \mathrm{ng} / \mu \mathrm{L}$ ) or of the primary PCR product, respectively, $0.2 \mu \mathrm{M}$ of each primer, and $15 \mu \mathrm{L}$ of $2 \times$ PCRBIO Taq Mix Red (PCR Biosystems, United Kingdom) in a total volume of $30 \mu \mathrm{L}$. The cycling conditions included an initial denaturation step at $94{ }^{\circ} \mathrm{C}$ for $3 \mathrm{~min}$, followed by 35 cycles of denaturation at $94{ }^{\circ} \mathrm{C}$ for $45 \mathrm{~s}$, annealing at $50{ }^{\circ} \mathrm{C}$ for $45 \mathrm{~s}$, and extension at $72{ }^{\circ} \mathrm{C}$ for $1 \mathrm{~min}$. Lastly, a final extension step at $72^{\circ} \mathrm{C}$ for $7 \mathrm{~min}$ was also included. Nuclease-free water and gDNA extracted from $10^{6}$ of Cryptosporidium parvum IOWA strain purified oocysts (Waterborne ${ }^{\mathrm{TM}}$, Inc., New Orleans, LA, USA) were used as a negative and positive control, respectively.

Secondary PCR products were separated by electrophoresis in a $2 \%(w / v)$ agarose gel $(2 \%)$ stained with ethidium bromide $(0.2 \mu \mathrm{g} / \mathrm{mL})$, and visualised under a UV light system (Syngene G:BOX Chemi XX6, UK). Bands of interest were excised from the gel and the DNA was purified using Thermo Scientific GeneJET Gel Extraction Kit (Thermo Fisher Scientific, CA, USA) following the manufacturer's instructions.

\subsection{Sequencing and Phylogenetic Analysis}

Bi-directional sequencing of the purified secondary PCR products was outsourced to Eurofins (UK), who performed Sanger sequencing with the set of the primers used for the secondary PCR reaction. The quality of both forward and reverse nucleotide sequences generated for the expected amplicons were then manually assessed and trimmed if necessary, with ChromasPro version 2.1.9 (http:/ / technelysium.com.au/wp/chromaspro/; accessed on 1 November 2020), assembled into a consensus sequence and mismatches corrected with the same software. The final assembled consensus sequence was then compared with GenBank reference sequences using the Basic Local Alignment Search Tool (BLAST) from the National Center for Biotechnology Information (NCBI) (http: / / blast.ncbi.nlm.nih.gov / Blast.cgi; accessed on 1 November 2020).

The sequences generated in this study were aligned with each other and with reference sequences from GenBank by MAFFT v.7 (https:/ / mafft.cbrc.jp/alignment/server; accessed on 15 January 2021) and the sequence alignment was manually inspected with BioEdit version 7.2.5 (https:/ / bioedit.software.informer.com; accessed on 15 January 2021). Phylogenetic analyses were performed and best DNA/Protein phylogeny models were selected using the MEGAX software $[47,48]$. Phylogenetic trees were inferred using maximum likelihood (ML), with the substitution model that best fit the alignment selected using the Bayesian information criterion. The Tamura 3-parameter model [49], was selected for SSU and gp60 alignments. Bootstrap support for branching was based on 1,000 replications. Phylograms were drawn using MEGAX and were manually adjusted and annotated using CorelDrawX7.

C. paroum allelic family and subtype was identified from the partial sequence of $g p 60$ gene based on the subtypes nomenclature reported previously [34]. The 18S rRNA and gp60 sequences derived in this study were deposited in GenBank. The accession numbers are: MW947282-MW947436 for 18S rRNA of C. parvum, MZ021416 for C. xiaoi, MZ021417MZ021429, MZ021431, MZ021433-MZ021436, MZ021438-MZ021441, MZ021443, MZ021445, MZ021447, MZ021449, MZ021451- MZ021461, MZ021464-MZ021467 and MZ021469-MZ021470 for 18S rRNA for C. bovis, MZ021426 for C. andersoni and MZ021430, MZ021432, MZ021437, MZ021442, MZ021444, MZ021446, MZ021448, MZ021450, MZ021462-MZ021463, MZ021468 
and MZ021471 for C. ryanae. The accession numbers MW996760-MW996892 are for the gp60 of C. parvum.

\section{Results}

\subsection{Sampling Report}

In this study, a total of 1084 faecal samples from 57 farms were collected. These included 545 faecal samples from dairy calves and 539 from cows. Twenty of these were located in the Netherlands, 20 in France, and 17 in Belgium (Figure 1). For each farm, between 6 and 41 faecal samples were collected (median 20 and mean of $18.4 \pm 4.4$ ) and a roughly even ratio of faecal sample collection from calves and their corresponding mother cows was obtained. The age of the tested calves varied from 0 to 106 days (14 median and mean of $21.6 \pm 21.1)$

\subsection{Cryptosporidium spp. Occurrence and Prevalence in Farms across Belgium, France, and the Netherlands}

Using amplification of a partial $18 S$ rRNA gene fragment with nested PCR revealed at least one animal tested positive for Cryptosporidium in $94.1 \%(n=17)$ farms in Belgium, $100 \%(n=20)$ in France and $85.0 \%(n=17)$ in the Netherlands. Considering all farms, the overall occurrence of Cryptosporidium at the farm level was $93.0 \%$ (53/57).

Within Belgium, Cryptosporidium spp. infections ranged from 5.0\% (1/20 cows, farm 9) to $40.0 \%$ (8/20 cows, farm 11$)$. Infection rates ranged between $5.6 \%$ (1/18 cows, farm 18$)$ to $50.0 \%$ (3/6 cows, farm 31) in France, while in the Netherlands rates varied between $5.0 \%$ $(1 / 20$ cows, farm 51) and 30.0\% (6/20 cows, farms 46, 50, 56 and 57) (Table 1).

In terms of animals, 63 out of 335 were positive for Cryptosporidium spp. (18.8\%) in Belgium, with young calves exhibiting a higher susceptibility $(31.2 \% ; n=170)$ to infection as opposed to adults $(6.1 \% ; n=165)$. In France, 79 out of the $350(22.6 \%)$ animals tested positive with a prevalence of $41.1 \%(n=175)$ in calves as opposed to $4.0 \%$ prevalence in adults $(n=175)$. Lastly, in the Netherlands' farms, 69 out of 399 animals $(17.3 \%)$ were positive, with $32.5 \%(n=200$ prevalence in calves compared to adults, $2.0 \%(n=199)$ (Table 2$)$.

Table 1. Distribution of Cryptosporidum spp. and C. parvum subtypes in all dairy cattle from the Netherlands, Belgium and France included in this study.

\begin{tabular}{|c|c|c|c|c|c|c|c|c|c|c|c|c|c|c|c|}
\hline \multirow[t]{2}{*}{ Country } & \multirow[t]{2}{*}{ Farm ID } & \multicolumn{2}{|c|}{$\begin{array}{c}\text { Number of } \\
\text { Screened/Positive } \\
\text { Animals }\end{array}$} & \multicolumn{2}{|c|}{ C. paroum } & \multicolumn{2}{|c|}{ C. bovis } & \multicolumn{2}{|c|}{$\begin{array}{c}C . \\
\text { andersoni }\end{array}$} & \multicolumn{2}{|c|}{ C. ryanae } & \multicolumn{2}{|c|}{ C.xiaoi } & \multicolumn{2}{|c|}{ gp60 Subtypes of C. parvum (n) } \\
\hline & & Calf & Cow & Calf & Cow & Calf & Cow & Calf & Cow & Calf & Cow & Calf & Cow & Calf & Cow \\
\hline \multirow{17}{*}{ Belgium } & BE1 & $7 / 3$ & $7 / 0$ & 3 & - & - & - & - & - & - & - & - & - & IiaA15G2R1 (3) & - \\
\hline & BE2 & $20 / 5$ & $21 / 3$ & 5 & 1 & - & 1 & - & - & - & 1 & - & - & IIaA15G2R1 (5) & IIaA15G2R1 (1) \\
\hline & BE3 & $9 / 4$ & $11 / 0$ & 3 & - & - & - & - & - & 1 & - & - & - & IIaA17G2R1 (2) & - \\
\hline & BE4 & $9 / 4$ & $10 / 1$ & 4 & 1 & - & - & - & - & - & - & - & - & IIaA15G2R1 (3) & IIaA15G2R1 (1) \\
\hline & BE5 & $10 / 4$ & $10 / 1$ & 2 & 1 & 1 & - & - & - & 1 & - & - & - & IIaA15G2R1 (2) & IIaA15G2R1 (1) \\
\hline & BE6 & $10 / 1$ & $10 / 1$ & 1 & 1 & - & - & - & - & - & - & - & - & IIaA15G2R1 (1) & - \\
\hline & BE7 & $10 / 4$ & $10 / 0$ & 2 & - & 1 & - & - & - & 1 & - & - & - & - & - \\
\hline & BE8 & $10 / 6$ & $10 / 1$ & 2 & - & 4 & 1 & - & - & - & - & - & - & IIaA15G2R1 (2) & - \\
\hline & BE9 & $10 / 1$ & $10 / 0$ & 1 & - & - & - & - & - & - & - & - & - & IIaA15G2R1 (1) & - \\
\hline & BE10 & $10 / 1$ & $8 / 0$ & - & - & 1 & - & - & - & - & - & - & - & - & - \\
\hline & BE11 & $10 / 6$ & $10 / 2$ & 6 & 2 & - & - & - & - & - & - & - & - & IIaA13G2R1 (6) & IIaA13G2R1 (2) \\
\hline & BE12 & $7 / 3$ & $1 / 0$ & - & - & 3 & - & - & - & - & - & - & - & - & - \\
\hline & BE13 & $10 / 4$ & $10 / 0$ & 4 & - & - & - & - & - & - & - & - & - & IIaA15G2R1 (4) & - \\
\hline & BE14 & $10 / 3$ & $10 / 0$ & 3 & - & - & - & - & - & - & - & - & - & IIaA16G3R1 (3) & - \\
\hline & BE15 & $10 / 0$ & $9 / 0$ & - & - & - & - & - & - & - & - & - & - & - & - \\
\hline & BE16 & $10 / 2$ & $10 / 1$ & - & 1 & 2 & - & - & - & - & - & - & - & - & - \\
\hline & BE17 & $8 / 2$ & $8 / 0$ & 2 & - & - & - & - & - & - & - & - & - & IIaA15G2R1 (2) & - \\
\hline
\end{tabular}


Table 1. Cont.

\begin{tabular}{|c|c|c|c|c|c|c|c|c|c|c|c|c|c|c|c|}
\hline \multirow[t]{2}{*}{ Country } & \multirow[t]{2}{*}{ Farm ID } & \multicolumn{2}{|c|}{$\begin{array}{l}\text { Number of } \\
\text { Screened/Positive } \\
\text { Animals }\end{array}$} & \multicolumn{2}{|c|}{ C. paroum } & \multicolumn{2}{|c|}{ C. bovis } & \multicolumn{2}{|c|}{$\begin{array}{c}C . \\
\text { andersoni }\end{array}$} & \multicolumn{2}{|c|}{ C. ryanae } & \multicolumn{2}{|c|}{ C.xiaoi } & \multicolumn{2}{|c|}{ gp60 Subtypes of C. paroum (n) } \\
\hline & & Calf & Cow & Calf & Cow & Calf & Cow & Calf & Cow & Calf & Cow & Calf & Cow & Calf & Cow \\
\hline \multirow{19}{*}{ France } & FR18 & $9 / 0$ & $9 / 1$ & - & 1 & - & - & - & - & - & - & - & - & - & IIaA16G2R1 (1) \\
\hline & FR19 & $11 / 3$ & $11 / 0$ & 3 & - & - & - & - & - & - & - & - & - & IIaA15G2R1 (3) & - \\
\hline & FR20 & $10 / 5$ & $10 / 0$ & 5 & - & - & - & - & - & - & - & - & - & IIaA15G2R1 (5) & - \\
\hline & FR21 & $10 / 6$ & $10 / 0$ & 6 & - & - & - & - & - & - & - & - & - & IIaA16G2R1 (6) & - \\
\hline & FR22 & $10 / 4$ & $10 / 1$ & & - & 3 & 1 & - & - & - & - & 1 & - & & - \\
\hline & FR23 & $10 / 7$ & $10 / 1$ & 7 & 1 & - & - & - & - & - & - & - & - & IIaA15G2R1 (7) & - \\
\hline & FR24 & $10 / 4$ & $10 / 3$ & - & - & 4 & 2 & - & 1 & - & - & - & - & - & - \\
\hline & FR25 & $10 / 4$ & $10 / 0$ & 3 & - & 1 & - & - & - & - & - & - & - & IIaA15G2R1 (3) & - \\
\hline & FR26 & $10 / 7$ & $10 / 0$ & 5 & - & 1 & - & - & - & 1 & - & - & - & IIaA16G2R1 (5) & - \\
\hline & FR27 & $9 / 5$ & $9 / 0$ & - & - & 4 & - & - & - & 1 & - & - & - & - & - \\
\hline & FR28 & $9 / 1$ & $10 / 1$ & - & - & 1 & - & - & - & - & 1 & - & - & - & - \\
\hline & FR29 & $5 / 2$ & $5 / 0$ & 2 & - & - & - & - & - & - & - & - & - & IIaA15G2R1 (2) & - \\
\hline & FR30 & $10 / 4$ & $10 / 0$ & 1 & - & 3 & - & - & - & - & - & - & - & IIaA16G1R1 (1) & - \\
\hline & FR31 & $3 / 3$ & $3 / 0$ & 3 & - & - & - & - & - & - & - & - & - & IIaA15G2R1 (3) & - \\
\hline & FR32 & $4 / 1$ & $4 / 0$ & 1 & - & - & - & - & - & - & - & - & - & - & - \\
\hline & FR33 & $7 / 3$ & $7 / 0$ & 3 & - & - & - & - & - & - & - & - & - & IIaA15G2R1 (3) & - \\
\hline & FR34 & $10 / 3$ & $10 / 0$ & 2 & - & 1 & - & - & - & - & - & - & - & IIaA15G2R1 (2) & - \\
\hline & FR35 & $11 / 4$ & $11 / 0$ & 4 & - & - & - & - & - & - & - & - & - & IIaA18G2R1 (4) & - \\
\hline & FR36 & $9 / 5$ & $9 / 0$ & 4 & - & & - & - & - & 1 & - & - & - & IIaA15G2R1 (2) & - \\
\hline \multirow{21}{*}{$\begin{array}{l}\text { The } \\
\text { Nether- } \\
\text { lands }\end{array}$} & FR37 & $8 / 1$ & $7 / 0$ & - & - & 1 & - & - & - & - & - & - & - & - & - \\
\hline & NL38 & $10 / 0$ & $10 / 0$ & - & - & - & - & - & - & - & - & - & - & - & - \\
\hline & NL39 & $10 / 0$ & $10 / 0$ & - & - & - & - & - & - & - & - & - & - & - & - \\
\hline & NL40 & $10 / 2$ & $9 / 0$ & 2 & - & - & - & - & - & - & - & - & - & - & - \\
\hline & NL41 & $10 / 2$ & $10 / 1$ & 1 & 1 & 1 & - & - & - & - & - & - & - & IIaA15G2R1 (1) & - \\
\hline & NL42 & $10 / 3$ & $10 / 0$ & 3 & - & - & - & - & - & - & - & - & - & IIaA15G2R1 (2) & - \\
\hline & NL43 & $10 / 0$ & $10 / 0$ & 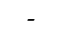 & - & - & - & - & - & - & - & - & - & - & - \\
\hline & NL44 & $10 / 4$ & $10 / 0$ & 3 & - & 1 & - & - & - & - & - & - & - & IIaA15G2R1 (3) & - \\
\hline & NL45 & $10 / 3$ & $10 / 0$ & 3 & - & - & - & - & - & - & - & - & - & IIaA13G2R1 (3) & - \\
\hline & NL46 & $10 / 5$ & $10 / 1$ & 3 & 1 & - & - & - & - & 2 & - & - & - & IIaA15G2R1 (2) & - \\
\hline & NL47 & $10 / 4$ & $10 / 1$ & 4 & 1 & - & - & - & - & - & - & - & - & IIaA15G2R1 (4) & - \\
\hline & NL48 & $10 / 5$ & $10 / 0$ & 5 & - & - & - & - & - & - & - & - & - & IIaA15G2R1 (5) & - \\
\hline & NL49 & $10 / 5$ & $10 / 0$ & 2 & - & 2 & - & - & - & 1 & - & - & - & IIaA15G2R1 (1) & - \\
\hline & NL50 & $10 / 6$ & $10 / 0$ & 6 & - & - & - & - & - & - & - & - & - & IIaA15G2R1 (6) & - \\
\hline & NL51 & $10 / 1$ & $10 / 0$ & & - & 1 & - & - & - & - & - & - & - & - & - \\
\hline & NL52 & $10 / 3$ & $10 / 1$ & 3 & - & - & 1 & - & - & - & - & - & - & IIaA14G1R1 (2) & - \\
\hline & NL53 & $10 / 2$ & $10 / 0$ & 1 & - & & - & - & - & 1 & - & - & - & - & - \\
\hline & NL54 & $10 / 3$ & $10 / 0$ & 3 & - & - & - & - & - & - & - & - & - & IIaA15G2R1 (3) & - \\
\hline & NL55 & $10 / 5$ & $10 / 0$ & 5 & - & - & - & - & - & - & - & - & - & IIaA15G2R1 (4) & - \\
\hline & NL56 & $10 / 6$ & $10 / 0$ & 6 & - & - & - & - & - & - & - & - & - & IIaA15G2R1 (5) & - \\
\hline & NL57 & $10 / 6$ & $10 / 0$ & 6 & - & - & - & - & - & - & - & - & - & IIaA15G2R1 (6) & - \\
\hline
\end{tabular}

Table 2. Prevalence and distribution of Cryptosporidium spp. and C. parvum subtypes in dairy cattle from the Netherlands, Belgium, and France.

\begin{tabular}{|c|c|c|c|c|c|c|c|c|}
\hline \multirow{2}{*}{ Country } & \multirow{2}{*}{ Age Group } & \multirow{2}{*}{$\begin{array}{c}\text { Number of } \\
\text { Screened/Positive } \\
\text { Animals }\end{array}$} & \multicolumn{5}{|c|}{ Genotyping and Number of Positive Samples (\%) } & \multirow{2}{*}{$\begin{array}{c}\text { Genotyping of } \\
\text { C. parvum at the gp60 } \\
(n / \%)\end{array}$} \\
\hline & & & C. paroum & C. bovis & C. andersoni & C. ryanae & C. xiaoi & \\
\hline \multirow{3}{*}{ Belgium } & Calf & $170 / 53$ & $38(73.1)$ & $12(23.1)$ & - & $3(5.8)$ & - & $\begin{array}{c}\text { IIaA15G2R1 (23/67.7), } \\
\text { IIaA17G2R1 (2/5.9), } \\
\text { IIaA13G2R1 (6/17.6), } \\
\text { IIaA16G3R1 (3/8.8) }\end{array}$ \\
\hline & Cow & $165 / 10$ & $7(70.0)$ & $2(20.0)$ & - & $1(10.0)$ & - & $\begin{array}{l}\text { IIaA15G2R1 (3/60.0), } \\
\text { IIaA13G2R1 (2/40.0), }\end{array}$ \\
\hline & Overall & $335 / 63$ & $45(71.4)$ & $14(22.2)$ & - & $4(6.4)$ & - & $\begin{array}{c}\text { IIaA15G2R1 (26/66.7), } \\
\text { IIaA17G2R1 (2/5.1), } \\
\text { IlaA13G2R1 (8/20.5), } \\
\text { IlaA16G3R1 (3/7.7) }\end{array}$ \\
\hline \multirow{3}{*}{ France } & Calf & $175 / 72$ & $49(68.1)$ & $19(26.4)$ & - & $3(4.2)$ & $1(1.3)$ & $\begin{array}{c}\text { IIaA15G2R1 (30/65.2), } \\
\text { IIaA16G2R1 (11/23.9), } \\
\text { IIaA16G1R1 (1/2.2), } \\
\text { IIaA18G2R1 (4/8.7) }\end{array}$ \\
\hline & Cow & $175 / 7$ & $2(28.6)$ & $3(42.8)$ & $1(14.3)$ & $1(14.3)$ & - & IIaA16G2R1 (1/100.0) \\
\hline & Overall & $350 / 79$ & $51(64.6)$ & $22(27.8)$ & $1(1.3)$ & $4(5.0)$ & $1(1.3)$ & $\begin{array}{c}\text { IIaA15G2R1 (30/63.8), } \\
\text { IIaA16G2R1 (12/25.6), } \\
\text { IIaA16G1R1 (1/2.1), } \\
\text { IIaA18G2R1 (4/8.5) }\end{array}$ \\
\hline \multirow{3}{*}{ Netherlands } & Calf & $200 / 65$ & $56(86.2)$ & $5(7.7)$ & - & $4(6.1)$ & - & $\begin{array}{c}\text { IIaA15G2R1 (42/89.4), } \\
\text { IIaA13G2R1 (3/6.4), } \\
\text { IIaA14G1R1 (2/4.2) }\end{array}$ \\
\hline & Cow & $199 / 4$ & $3(75.0)$ & $1(25.0)$ & - & - & - & - \\
\hline & Overall & $399 / 69$ & $59(85.5)$ & $6(8.7)$ & - & $4(5.8)$ & - & $\begin{array}{c}\text { IIaA15G2R1 (42/89.4), } \\
\text { IIaA13G2R1 (3/6.4), } \\
\text { IIaA14G1R1 (2/4.2) }\end{array}$ \\
\hline
\end{tabular}




\subsubsection{Belgium}

In Belgian farms, 63 animals were identified as Cryptosporidium spp. with 45 cases (71.4\%) identified as C. parvum, $14(22.2 \%)$ as C. bovis and four as C. ryanae $(6.4 \%)$. In calves C. parvum was identified in 38 cases $(73.1 \%)$, while $12(23.1 \%)$ were shown to be C. bovis, and three $(5.8 \%)$ were assigned as $C$. ryanae. In adult dairy cows, we identified seven positives $(70.0 \%)$ for C. parvum, two $(20.0 \%)$ for C. bovis and one for C. ryanae $(10.0 \%)$ (Table 2). Sequence analysis of the $18 \mathrm{~S}$ rRNA for C. parvum isolates revealed $100 \%$ nucleotide identity to the AH006572 reference sequence for 44 sequences (accession numbers MW947333-MW947340 and MW947342- MW947377) and 99\% nucleotide identity to AH006572 reference sequence for the remaining sequences detected (accession number MW947341, displaying an A-to-T transversion at position 223, and an A-to-G transition at position 562). Sequence analysis of the $C$. bovis isolates, revealed $100 \%$ nucleotide identity to the AB777173 reference sequence for 12 sequences (MZ021445, MZ021447, MZ021449, MZ021451-MZ021457 and MZ021460-MZ021461) and 99\% nucleotide identity to the AB777173 reference sequence for two sequences (MZ021458- MZ021459). C. ryanae isolates exhibited a $100 \%$ nucleotide identity to the reference sequence FJ463193 for four sequences (MZ021444, MZ021446, MZ021448 and MZ021450) (Figure 2).

\subsubsection{France}

In France, a total of 79 samples tested positive for Cryptosporidium spp. with C. parvum being identified in 51 cases $(64.6 \%)$, C. bovis in $22(27.8 \%)$, C. ryanae in four $(5.0 \%)$, C. andersoni in one $(1.3 \%)$ and C. xiaoi in one $(1.3 \%)$. In calves, 49 cases $(68.1 \%)$ of C. parvum were detected, while C. bovis was identified in 19 cases $(26.4 \%)$, C. ryanae in three $(4.2 \%)$ and C. xiaoi in one (1.3\%). In cows, C. bovis was observed in three cases $(42.8 \%)$ C. paroum in two $(28.6 \%)$, C. andersoni in one $(14.3 \%)$ and C. ryanae also in only one case $(14.3 \%)$ (Table 2). Sequence analysis of $18 S \mathrm{rRNA}$ for C. parvum isolates, revealed $100 \%$ nucleotide identity to the AH006572 reference sequence for 51 sequences (accession numbers MW947282-MW947332). Similar sequence analysis for C. bovis isolates, revealed 100\% nucleotide identity to AB777173 reference sequence for 20 sequences (MZ021416-MZ021425, MZ021427-MZ021429, MZ021431, MZ021433-MZ021434, MZ021436, MZ021438-MZ021440 and MZ021443) and $99 \%$ nucleotide identity to the AB777173 reference sequence for two sequences (MZ021435 and MZ021441). C. ryanae isolates exhibited a 100\% nucleotide identity to the FJ463193 reference sequence for four sequences (MZ021430, MZ021432, MZ021437 and MZ021442). Lastly, sequence analysis for C. andersoni isolate, revealed 100\% nucleotide identity to the AB513856 reference sequence for the one sequence (MZ021426) while the C. xiaoi isolate (MZ021416) exhibited a 100\% nucleotide identity to the FJ896046 reference sequence (Figure 2).

\subsubsection{The Netherlands}

Out of the 69 samples shown to be Cryptosporidium spp. positive in the Netherlands, the majority of those (59 cases; $85.5 \%$ ) were assigned as C. parvum while the remaining samples were identified as $C$. bovis, ( 6 cases; $8.7 \%$ ) and $C$. ryanae ( 4 cases; $5.8 \%)$. In calves, C. parvum was identified in 56 animals $(86.2 \%)$, C. bovis in five $(7.7 \%)$ and C. ryanae in four $(6.1 \%)$. Out of the four positive cases in adult cows, three $(75.0 \%)$ were identified as $C$. parvum, while the remaining one was C. bovis (25.0\%) (Table 2). Further sequence analysis of the $18 \mathrm{~S}$ rRNA gene for the $C$. parvum isolates, revealed $100 \%$ nucleotide identity to the AH006572 reference sequence for the 59 sequences detected in this study (accession numbers MW947378-MW947436). Sequence analysis for the C. bovis isolates, revealed $100 \%$ nucleotide identity to the AB777173 reference sequence for six samples (MZ021464MZ021467 and MZ021469-MZ021470). Sequence analysis of the $C$. ryanae isolates presented a $100 \%$ nucleotide identity to the reference sequence FJ463193 for four cases (MZ021462MZ021463, MZ021468 and MZ021471) (Figure 2). 


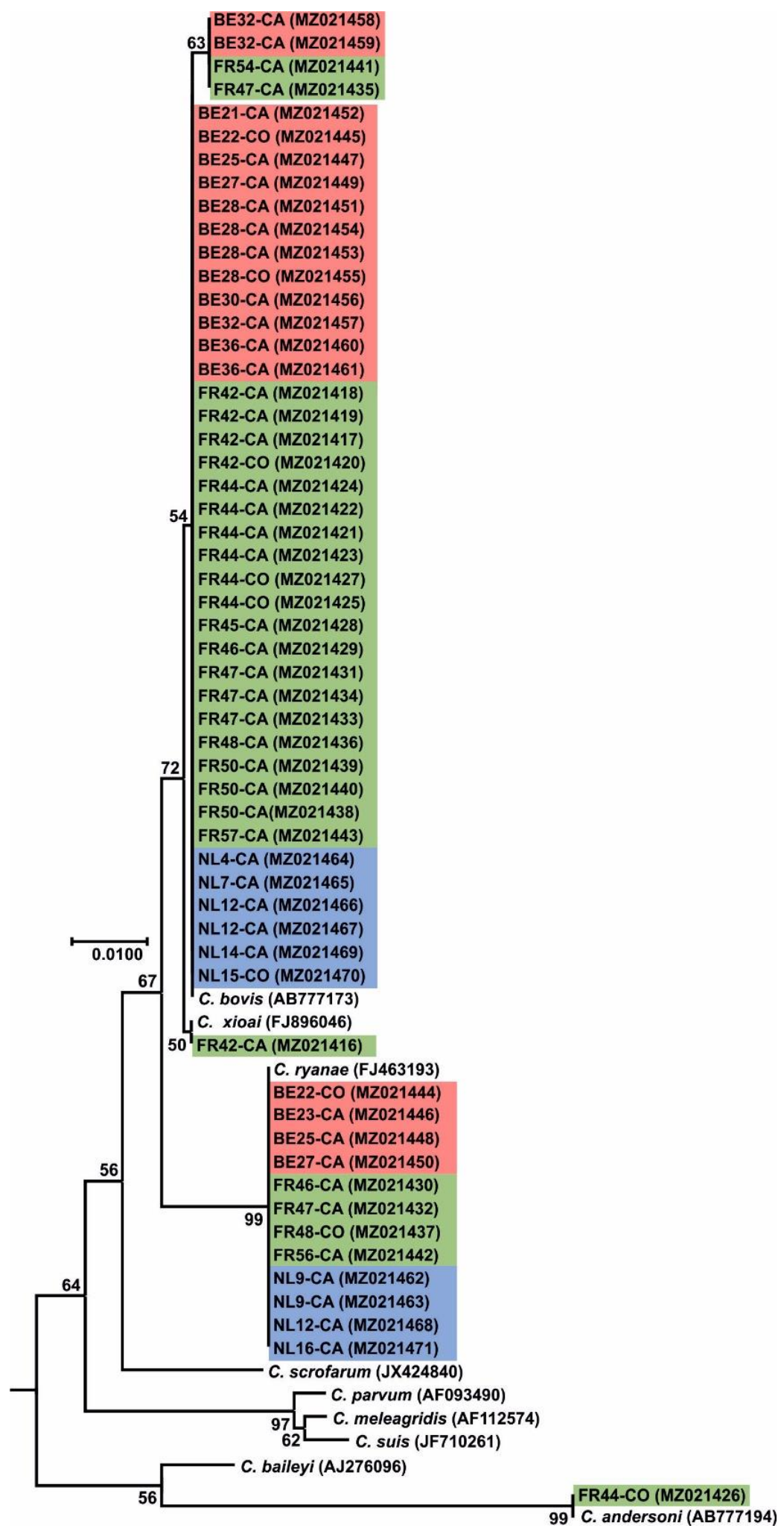

Figure 2. A maximum likelihood (ML) tree based on the $18 \mathrm{~S}$ rRNA gene sequences of C. bovis, C. ryanae, C. xioai and C. andersoni obtained in this study. Bootstrap values for the nodes with more than $50 \%$ support are shown. Sequences from this study are identified by country (NL for the Netherlands and highlighted in blue; BE for Belgium and highlighted in red; FR for France and highlighted in green), number of the farm (e.g., NL4), and host age (CA for calf and CO for cow). The ML tree was rooted with an 18S rRNA sequence from Monocystis agilis (accession number: AF457127). The GenBank accession number for each sequence is mentioned in parenthesis. 


\subsubsection{Cryptosporidium parvum Subtyping through gp60 Molecular Analysis}

Using $18 S$ rRNA sequencing and phylogenetic analyses, a total of 155 samples were identified as C. parvum positive. PCR products of the gp60 gene were successfully obtained for $137(88.4 \%)$ of these cases. Sequence analysis and subsequent subtyping revealed the presence of eight different subtypes belonging to the IIa subtype family (Figure 3).

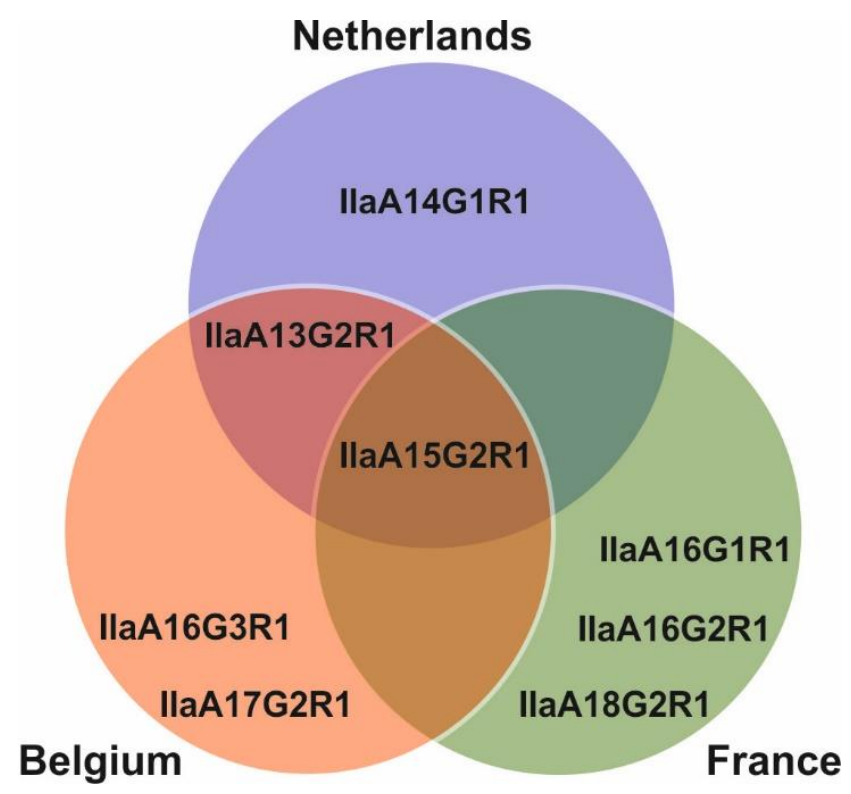

Figure 3. Venn diagram with all observed C. parvum gp60 subtypes across Belgium, France, and the Netherlands.

At least one subtype of the IIa family was found to circulate in $70 \%(n=20)$ of farms in the Netherlands, $70.6 \%(n=17)$ in Belgium and $70.0 \%(n=20)$ in France. Regarding, the distribution of subtypes between calves and cows, in the Netherlands, all $47(100 \%)$ of the subtypes identified were solely found in calves, while in Belgium $34(87.2 \%)$ subtypes were described in calves and the remaining five subtypes (12.8\%) in adults. Lastly, for French farms, 46 subtypes $(97.9 \%)$ were identified in calves and only one subtype was identified in adults (2.1\%) (Tables 1 and 2).

Subtype IIaA15G2R1 (100\% identity to the reference sequence MK099855) was present in all three countries and was also the most widespread. In the Netherlands, Belgium, and France, this subtype was identified in $89.4 \%$ (42 out 47 ), $66.7 \%$ (26 out of 39 ), and $63.8 \%$ (30 out of 47) cases, respectively. In the Netherlands, this subtype was found in $70.6 \%$ (12 out of 17) farms which tested positive for C. parvum, while in Belgium and France this subtype was found in $64.3 \%$ (9 out of 14 ) and $60.0 \%$ (9 out of 15) farms, respectively. In the Netherlands, this subtype was only reported in calves, in $89.4 \%$ (42 out 47 ) infections, while in Belgium $67.7 \%$ (23 out of 34 ) calves and three out of five (60.0\%) adults were found to have this subtype. Lastly, in France, this subtype was only detected in calves, in $65.2 \%$ (30 out of 46) infections.

The second most reported subtype in this study was IIaA16G2R1 (100\% identity to the reference sequence MG516787), with all 12 isolates exclusively identified in France. This subtype was observed in 20\% (3 out of 15) French farms that tested positive for C. parvum. Its presence was mainly in calves (23.9\%; 11 out of 46 infections), with only one report in an adult cow. The third most abundant subtype was IlaA13G2R1 (100\% identity with reference sequence MN815775), with 11 isolates distributed through the Netherlands and Belgium. This subtype was found in just 1 out of the 17 (5.9\%) Dutch farms which tested positive for C. parvum, and only in three calves out of 47 (6.4\%). In Belgium, this subtype was also found in just one out of $12(8.3 \%)$ farms which tested positive for C. parvum, with six out $34(17.6 \%)$ calves and two out five (40.0\%) cows testing positive for 
this subtype. The remaining five subtypes were: IIaA14G1R1, which was only observed in the Netherlands (99\% identity to the reference sequence, AM937017 missing an adenine nucleotide at position 45); IIaA17G2R1 and IIaA16G3R1, which were only observed in Belgium (100\% identity to the reference sequences, MG516783 and DQ192506, respectively); and IIaA16G1R1 and A18G2R1, which were only observed in France (100\% identity to the reference sequences, KJ158747 and MK391451, respectively). All these subtypes were found in only a single farm and exclusively in calves (Figure 1).

\section{Discussion}

Cryptosporidium is the causative agent of cryptosporidiosis in humans and other animals. In the farming industry, cryptosporidiosis is a major concern among livestock. C. paroum, in particular, is considered to be a major cause of disease in neonatal calves, resulting in profuse diarrhoea and in extreme cases even death [13]. Herein, we employed molecular techniques based on 18S DNA and gp60 gene analysis aimed to assess Cryptosporidium spp. prevalence as well as perform subtyping of C. parvum among cattle in several dairy farms distributed across three countries. The contribution of several factors in C. parvum spreading was also evaluated. Our analyses revealed that the average prevalence of Cryptosporidium spp. in screened farms, was 93.0\%, with France having the highest at $100 \%$, followed by Belgium at $94.1 \%$ and the Netherlands at $85.0 \%$. These results are in line with previous epidemiological studies recorded in beef and dairy farms in France. For instance, Follet et al., (2011) reported the presence of Cryptosporidium spp. in all examined beef farms following molecular detection using the $18 S$ rRNA gene, while Mammeri et al., (2019) described the presence of Cryptosporidium spp. on $92.3 \%$ of dairy farms using direct immunofluorescence assay (DFA) screening. Interestingly, in Belgium, the only published study in dairy farms reported the presence of Cryptosporidium spp. on 32 out of 100 farms $(32.0 \%)$ using quantitative immunofluorescence assay (IFA) for parasite detection [43]. In the Netherlands, the only study carried out to assess Cryptosporidium spp. prevalence in cattle did not provide any information on Cryptosporidium spp. per farm occurrence [44]. Similar prevalence studies in Europe, employing nested PCR targeting the $18 S$ gene, documented less overall occurrence of Cryptosporidium spp. with $44.5 \%$ in Spanish dairy and beef farms, $62.3 \%$ in dairy farms of Estonia [50,51] and, in the Czech Republic, 79.2\% in calves and $30.4 \%$ in cows [52,53]. In Germany and Italy, following microscopy methods for Cryptosporidium spp. detection, it was also observed a lower prevalence of the parasite at farm level with $68.2 \%$ in Italian dairy farms and a $70.0 \%$ prevalence in German calf farms [54,55]. A common issue between all these studies is the lack of consistent methods for sampling and parasite detection, which will allow accurate comparisons between them while avoiding detections bias.

At the individual level, by country, Belgium, France and the Netherlands totalled $18.8 \%, 22.6 \%$, and $17.3 \%$ prevalence, respectively, of Cryptosporidium spp. infection out of all sampled animals. Past studies in France reported higher Cryptosporidium spp. infections in beef and dairy calves (ranging from 41.5 to $100 \%$ ) [36,37,39,41,42,56]. Moreover, previous reports from Belgium also demonstrated slightly higher infections (37.0\%) in dairy calves while, to our knowledge, no such information is available for the Netherlands [43]. In nearby European countries, such as Germany, United Kingdom, Austria, Spain, and Italy prevalence of Cryptosporidium spp. in beef and dairy calves assessed using molecular, immunological or microscopy screening, varied between $16.7 \%$ and $100 \%[51,54,55,57,58]$. These data seem to correlate with equivalent findings worldwide where livestock parasite infections appear to lessen with the increase in age of cattle $[19,27,59-65]$. However, two recent studies carried out in dairy and beef farms in the United Kingdom pointed towards much higher infection rates in adult cattle with a reported Cryptosporidium spp. prevalence of roughly $80.0 \%$ in both studies, which was attributed to improved sensitivity in methods used during both investigative works $[58,66]$. The observed variances in reported infections might stem from distinct geographical locations in association with climate variations but also due to differences linked to the study design, with factors such as sample size, age, 
herd size, total number of farms investigated, farm management practices and screening methods applied playing an important factor [13].

Age-related infection predisposition to different Cryptosporidium species was also observed in our results after nested PCR analysis of the $18 S$ gene. Cryptosporidium parvum was clearly the dominant species in calves in all three countries, followed by C. bovis, C. ryanae and C. xiaoi, the latter having been observed in a single calf in France. Previous molecular studies conducted in dairy and beef calves in France and Belgium support our findings, with $C$. parvum being also the predominant infective species in pre-weaned beef and dairy calves $[36,37,40,43]$. Other molecular studies across Europe also seem to indicate C. paroum as the dominant Cryptosporidium species in pre-weaned calves $[50-52,54,58,67]$. The presence of $C$. bovis was less prominent in calves from this study, but this species has been reported in some parts of Europe and across the world as the major infecting species in beef and dairy calves [25,68-77]. Cryptosporidium ryanae was sporadically detected in calves across the three countries, which seem to be consistent with other molecular studies performed in beef and dairy farms in France and in other parts of Europe [25,36,41,50-52,58,74]. This species was, to our knowledge, observed for the first time in cattle from the Netherlands and Belgium. Both $C$. bovis and C. ryanae are mostly associated with infections in post-weaned calves and have yet been linked with cryptosporidiosis illness [13,78]. Cryptosporidium xiaoi, the host-specific species for sheep [79], was only recorded in one calf in France herein. Reports of infection in cattle are scarce; however, this species is reported occasionally in Jordan, China and Spain [51,80,81]. In Ireland, infections in cattle were reported as C. bovis/C. xiaoi due to the inability of distinguishing the two at the $18 \mathrm{~S}$ rRNA gene level [79,82]. Previous cattle infections with $C$. xiaoi were either attributed to cross-infections between livestock sharing the same grazing fields or due to contact with contaminated water $[51,80]$. To our knowledge, none of the farms included in this project had any association with other (small ruminants), thus the source of $C$. xiaoi remains unresolved.

The preponderance of $C$. parvum infections in calves has been debated before, with some studies suggesting that calves with $C$. parvum infections shed oocysts at a higher density when compared to other infective species, such as C. bovis or $C$. ryanae. The increased shed could lead to a preferential DNA amplification of the dominant $C$. parvum in a sample during $18 S$ rRNA gene-targeted PCR while, at the same time, masking the infection by other Cryptosporidium species and suppressing their detection [59,83-85]. Previous molecular studies in cattle mention C. andersoni as the primary force behind Cryptosporidium infections in adult cows $[18,27,59,86]$. However, in the present study, C. parvum was the dominant species infecting cows in the Netherlands $(75 \%)$ and Belgium $(70 \%)$, which was similar to what was reported in two recent studies carried out in United Kingdom cattle farms, which might indicate that adults shed C. paroum oocysts more frequently than previously thought $[58,66]$. Additionally, reports from Spain also documented lower C. andersoni infections in adult cows in cattle farms and instead found C. bovis as the main species present in adult cattle, as observed in our study in France [51]. These results might indicate that $C$. anderson $i$ is not as predominant in adult cattle as previously thought, and the established Cryptosporidium spp. age-related prevalence is not necessarily uniform across different regions.

To further explore the genetic diversity within C. parvum and assess potential zoonotic transmission, subtype assessment was undertaken through gp60 locus analysis. In total, eight different subtypes were detected across the three countries and, notably, all belonged to the IIa zoonotic allelic family. The IIa allele is exceptionally prevalent in young cattle and has been linked with various occurrences of zoonotic transmission (both sporadic and outbreak cases) of $C$. parvum in Europe $[6,35,87]$. Subtype IlaA15G2R1 was found to be the most prevalent in all countries with the Netherlands reporting a total prevalence rate of $89.4 \%$, Belgium at a total of $66.7 \%$ and France a total of $63.8 \%$. In western mainland Europe, the IIaA15G2R1 subtype was previously described as the most prevalent in cattle [36,37,40,42-44]. Similar observations were reported in other European countries, including Portugal, Italy, Spain, Germany, Czech Republic, Austria, Slovenia, and the United Kingdom [20,51,52,54,55,57,66,67,88] 
and in other parts of the world such as Japan and Uruguay $[89,90]$. IIaA15G2R1 is deemed as the most prevalent IIa subtype in humans in developed countries, with several cases of human cryptosporidiosis linked to it $[6,44,67,87,88,91-93]$. Several previous outbreaks with this subtype in the United Kingdom were traced back to contact between farm animals and humans pointing towards zoonotic potential [35]. In fact, it has been speculated that this subtype is hyper-transmissible, which might explain its preponderance in zoonotic infections across the world [3].

The second most documented subtype was IIaA16G2R1, with all occurrences being detected in French farms, and with a prevalence of $25.6 \%$. This subtype was previously described in cattle of France with a much lower prevalence of just 3.9\% [36]. Interestingly, this subtype was also previously observed in cattle located in Belgium and the Netherlands $[43,44]$. Cattle infected with this subtype was also previously found in other parts of Europe, including Portugal, Germany, Spain and Estonia [50,55,88,94]. IIaA16G2R1, has been known to cause sporadic human cryptosporidiosis in a few countries, namely New Zealand, Canada, Spain, and Jordan [91,92,95-97].

The third most abundant subtype in our study was IIaA13G2R1, which occurred only in the Netherlands and Belgium, with a total prevalence of $6.4 \%$ and $20.5 \%$, respectively. This subtype has been found previously in both countries at lower frequencies than the ones reported herein, with a prevalence of $1.5 \%$ in both the Netherlands and Belgium $[43,44]$. From all other European countries, so far this subtype has only been reported in the United Kingdom [20]. This C. parvum subtype appears to be uncommon among calves with only Algeria, Turkey and Canada reporting its occurrence [98-100]. IIaA13G2R1 also has a low prevalence in humans with confirmed cases in Malaysia, South Korea, New Zealand, and Canada and thus its zoonotic potential is considered low [91-93,101].

The remaining five subtypes detected in this study had a low prevalence in all the studied countries, with less than five occurrences in each. To our knowledge, subtype IIaA14G1R1, which was only detected in the Netherlands, was for the first time described in this country and its lower prevalence $(4.2 \%)$ seems consistent with other reported frequencies in cattle across various European countries such as Germany, Poland, Austria, and Estonia [50,55,57,102]. Cryptosporidiosis cases in humans for this subtype have been documented in New Zealand, Canada, Slovenia and Slovakia [67,91,92,103].

Subtypes IIaA16G3R1 and IIaA17G2R1 were only found in Belgium and were for the first time described in this country, with a $7.7 \%$ and $5.1 \%$ prevalence, respectively. Subtype IIaA16G3R1 presence was previously described in France and the Netherlands, with similar frequencies $[36,40,44]$. Subtype IIaA17G2R1 was only observed before in the Netherlands with also with a similar frequency to that observed in this study, though two studies conducted in French river and sea waters reported the presence of this subtype on fish $[44,104,105]$. Subtype IIaA16G3R1 has been found in cattle in several European countries, such as Germany, Italy, Spain, Poland, and the United Kingdom [20,51,54,55,102,106]. Subtype IIaA17G2R1 has been found in cattle in Slovakia, Poland, Spain, Germany, and the United Kingdom [20,55,94,102,106,107]. Both subtypes have been previously observed in humans in New Zealand, Canada, Denmark, and Iran [87,91,92,97,108].

Lastly, subtypes IIaA18G2R1 and IIaA16G1R1 were found only in France with a prevalence of $8.5 \%$ and $2.1 \%$, respectively. Similar studies in France found both subtypes present in calves with one study reporting a similar prevalence of IIaA16G1R1 to the one reported in this present study [36], while another study found the IIaA18G2R1 to be the most prevalent in beef calves [41]. Subtype IIaA16G1R1 has also been observed before in the Netherlands, with a similar prevalence to the one reported in our study [44]. Subtype IIaA16G1R1 has also been reported in cattle from other European countries, including Sweden, the Czech Republic, Hungary, Poland, Romania, Slovenia, Germany and Estonia, [50,52,55,67,69,74,75,102,109,110], while subtype IIaA18G2R1 has been described before in cattle from Germany and the United Kingdom [58,66,106,111]. Human infections with these subtypes have also previously been detected in New Zealand, Canada, Sweden, Slovakia, Slovenia, Estonia, and the United Kingdom [35,67,91,92,103,112,113]. 
Through this study, only one subtype per farm was observed which might indicate endemicity at the farm level confirming results from previous studies $[40,67,102]$. This lack of genetic diversity may not be the rule though, with recent reports finding that more than one subtype per farm might be the norm $[20,37,50,54,55]$. The lack of genetic diversity per farm in our study might stem from the approach used, since conventional C. parvum gp60 subtyping with Sanger sequence only targets the dominant subtype. The application of next-generation sequencing (NGS) and/or single cell genomics [114-116] could provide a more reliable way to unearth the real multiplicity of $C$. parvum within a herd and within the same host. In fact, two reports using NGS described up to ten individual subtypes per sample in cattle and human isolates [117,118].

Another aim of this study was to investigate the possible role of mothers in transmitting the parasite to their newborn calves. Previous investigations on the subject were conducted before the advent of molecular subtyping tools thus no conclusions could be made. A recent paper addressed this issue with gp60 molecular subtyping [58]. The subtype analysis in our study and in agreement with the previous $18 S$ rRNA data analysis yielded a much higher amount of C. paroum genetic information in calves than in adults. After gp60 analysis, only two pairs of adults and calves were found to share the same C. parvum subtype, one pair in farm 5 and the other in farm 11, both located in Belgium. This suggests that there is no clear link for maternal transmission of the parasite. A similar and recently published work also looked into this hypothesis and did not find a strong link in the spread of C. parvum between adults and calves, finding that calves and adults shed different C. parvum subtypes [58]. However, it is possible that standard gp60 molecular and Sanger sequencing methods employed in this study might not have been discriminatory enough to uncover the true diversity of subtypes due to bias [116-118]. Moreover, sample collection occurred at a single time point instead of several. Thus the possibility of various additional subtypes going undetected due to differential shedding cycles cannot be excluded [58]. Although no strong evidence could be gathered regarding the source of infection of Cryptosporidium spp. within the farms, recent studies have started to investigate alternatives sources of transmission from outside the farms. For instance, zoonotic C. parvum subtypes sampled in cattle from UK farms were identical to those circulating in wildlife nearby, particularly in birds and deer [20,66]. Remarkably, the same zoonotic C. parvum was also found in water bodies within/nearby the farms thus water might be an alternative route of Cryptosporidium transmission in cattle and, eventually, transmission to humans. Thus farmers should consider implementing better water and farm management systems to prevent further environmental spread and contamination [20,66]. Moreover, although C. parvum transmission and infection are largely associated with mammals, recent studies conducted in aquatic environments highlighted its presence in edible fish (sea and freshwater), raising awareness for the importance of cattle as a source of environmental contamination and dispersion of Cryptosporidium spp. oocysts, since most of the fish were affected by the C. parvum subtype IIa [104,105]. Therefore, suitable farm practises that improve animal well-being and decrease occupational risks to humans in close contact with cattle should be implemented while better farm management systems to prevent further environmental spread and contamination should also be applied.

\section{Conclusions}

This study provides a detailed view of Cryptosporidium spp. prevalence across dairy cattle farms in Western Europe and is the first study in dairy farms in the Netherlands. Our findings indicate that Cryptosporidium spp. is widespread across dairy farms, with zoonotic C. parvum being the dominant species detected in calves across all the three countries included in this study. In addition, all the C. parvum subtypes identified in this study have been linked with cryptosporidiosis in humans, highlighting the potential of cattle as a reservoir for $C$. parvum. Our study also provides evidence that it is unlikely that adult cattle play a role as a source of infection, as sharing of $C$. parvum subtypes between adults and calves were only documented in two cases. However, it is important to note that other 
sources of infection could not be ruled out. Thus, follow-up studies should be conducted to assess cross-border and worldwide Cryptosporidium spp. prevalence, epidemiology, and transmission while considering a one-health approach on tackling cryptosporidiosis.

Author Contributions: Conceptualization, J.F., A.D.T., A.B.B. and H.L.; methodology, P.P., C.A.R., S.H., O.H., H.L., S.D., E.C., Y.D., M.D., J.R. and A.B.B.; software, M.K.; validation, P.P., M.K. and A.D.T.; formal analysis, O.H. and P.P.; investigation, P.P., C.A.R. and S.H.; resources, A.D.T. and M.K.; data curation, M.K.; writing-original draft preparation, P.P.; writing—review and editing, J.F., H.L. M.K. and A.D.T.; supervision, A.D.T. and J.F.; project administration, J.F.; funding acquisition, J.F. and A.D.T. All authors have read and agreed to the published version of the manuscript.

Funding: This project has received funding from the Interreg 2 Seas programme 2014-2020 co-funded by the European Regional Development Fund under subsidy contract No 2S05-043.

Institutional Review Board Statement: This study was only focusing on the collection of the faecal samples from selected dairy cows under the supervision of expert veterinarians and thus there were no ethical implications. Consequently, there was no need for perusal of any further ethical approvals.

Informed Consent Statement: Not applicable.

Data Availability Statement: All data have been submitted to GenBank as shown in the methods section.

Acknowledgments: We would like to thank the farmers in the 2-seas region for volunteering and working with us on this project. Lastly, we would like to thank Eleni Gentekaki from Mae Fah Luang University (Thailand) for providing us constrictive feedback on the manuscript.

Conflicts of Interest: The authors declare no conflict of interest.

\section{References}

1. Tandel, J.; English, E.D.; Sateriale, A.; Gullicksrud, J.A.; Beiting, D.P.; Sullivan, M.C.; Pinkston, B.; Striepen, B. Life cycle progression and sexual development of the apicomplexan parasite Cryptosporidium Parvum. Nat. Microbiol. 2019, 4, $2226-2236$. [CrossRef]

2. Xiao, L. Molecular epidemiology of cryptosporidiosis: An update. Exp. Parasitol. 2010, 124, 80-89. [CrossRef]

3. Feng, Y.; Ryan, U.M.; Xiao, L. Genetic Diversity and Population Structure of Cryptosporidium. Trends Parasitol. 2018, 34, 997-1011. [CrossRef] [PubMed]

4. Checkley, W.; White, A.C.; Jaganath, D.; Arrowood, M.J.; Chalmers, R.M.; Chen, X.M.; Fayer, R.; Griffiths, J.K.; Guerrant, R.L.; Hedstrom, L.; et al. A review of the global burden, novel diagnostics, therapeutics, and vaccine targets for Cryptosporidium. Lancet Infect. Dis. 2015, 15, 85-94. [CrossRef]

5. Ryan, U.; Fayer, R.; Xiao, L. Cryptosporidium species in humans and animals: Current understanding and research needs. Parasitology 2014, 141, 1667-1685. [CrossRef]

6. Cacciò, S.M.; Chalmers, R.M. Human cryptosporidiosis in Europe. Clin. Microbiol. Infect. 2016, 22, 471-480. [CrossRef]

7. Innes, E.A.; Chalmers, R.M.; Wells, B.; Pawlowic, M.C. A One Health Approach to Tackle Cryptosporidiosis. Trends Parasitol. 2020, 36, 290-303. [CrossRef]

8. Bouzid, M.; Hunter, P.R.; Chalmers, R.M.; Tyler, K.M. Cryptosporidium Pathogenicity and Virulence. Clin. Microbiol. Rev. 2013, 26, 115-134. [CrossRef]

9. Brainard, J.; Hooper, L.; McFarlane, S.; Hammer, C.C.; Hunter, P.R.; Tyler, K. Systematic review of modifiable risk factors shows little evidential support for most current practices in Cryptosporidium management in bovine calves. Parasitol. Res. 2020, 119, 3571-3584. [CrossRef] [PubMed]

10. Shaw, H.J.; Innes, E.A.; Morrison, L.J.; Katzer, F.; Wells, B. Long-term production effects of clinical cryptosporidiosis in neonatal calves. Int. J. Parasitol. 2020, 50, 371-376. [CrossRef]

11. Brook, E.; Hart, C.A.; French, N.; Christley, R. Prevalence and risk factors for Cryptosporidium spp. infection in young calves. Vet. Parasitol. 2008, 152, 46-52. [CrossRef] [PubMed]

12. Brainard, J.; Hammer, C.C.; Hunter, P.R.; Katzer, F.; Hurle, G.; Tyler, K. Efficacy of halofuginone products to prevent or treat cryptosporidiosis in bovine calves: A systematic review and meta-analyses. Parasitology 2021, 148, 408-409. [CrossRef] [PubMed]

13. Thomson, S.; Hamilton, C.A.; Hope, J.C.; Katzer, F.; Mabbott, N.A.; Morrison, L.J.; Innes, E.A. Bovine cryptosporidiosis: Impact, host-parasite interaction and control strategies. Vet. Res. 2017, 48, 42. [CrossRef] [PubMed]

14. Bennett, R.; IJpelaar, J. Updated Estimates of the Costs Associated with Thirty Four Endemic Livestock Diseases in Great Britain: A Note. J. Agric. Econ. 2005, 56, 135-144. [CrossRef]

15. Shaw, H.J. Digest Paper-cryptosporidiosis in calves, the economic impact and best control measures. Br. Cattle Breed. Club 2014, 69. Available online: https:/ / www.cattlebreeders.org.uk/digests/73/papers/1109/ (accessed on 20 November 2021). 
16. Fayer, R.; Santín, M.; Trout, J.M.; Greiner, E. Prevalence of species and genotypes of Cryptosporidium found in 1-2-year-old dairy cattle in the eastern United States. Vet. Parasitol. 2006, 135, 105-112. [CrossRef]

17. Fayer, R.; Santin, M.; Trout, J.M. Prevalence of Cryptosporidium species and genotypes in mature dairy cattle on farms in eastern United States compared with younger cattle from the same locations. Vet. Parasitol. 2007, 145, 260-266. [CrossRef]

18. Santín, M.; Trout, J.M.; Fayer, R. A Longitudinal study of cryptosporidiosis in dairy cattle from birth to 2 years of age. Vet. Parasitol. 2008, 155, 15-23. [CrossRef]

19. Santín, M.; Trout, J.M.; Xiao, L.; Zhou, L.; Greiner, E.; Fayer, R. Prevalence and age-related variation of Cryptosporidium species and genotypes in dairy calves. Vet. Parasitol. 2004, 122, 103-117. [CrossRef]

20. Smith, R.P.; Clifton-Hadley, F.A.; Cheney, T.; Giles, M. Prevalence and molecular typing of Cryptosporidium in dairy cattle in England and Wales and examination of potential on-farm transmission routes. Vet. Parasitol. 2014, 204, 111-119. [CrossRef]

21. Wang, R.; Zhao, G.; Gong, Y.; Zhang, L. Advances and Perspectives on the Epidemiology of Bovine Cryptosporidium in China in the Past 30 Years. Front. Microbiol. 2017, 8, 2013-2018. [CrossRef] [PubMed]

22. Wang, Y.; Cao, J.; Chang, Y.; Yu, F.; Zhang, S.; Wang, R.; Zhang, L. Prevalence and molecular characterization of Cryptosporidium spp. and Giardia duodenalis in dairy cattle in Gansu, northwest China. Parasite 2020, 27, 1-9. [CrossRef] [PubMed]

23. Fayer, R.; Santín, M.; Xiao, L. Cryptosporidium bovis n. sp. (Apicomplexa: Cryptosporidiidae) in cattle (Bos taurus). J. Parasitol. 2005, 91, 624-629. [CrossRef] [PubMed]

24. Fayer, R.; Santín, M.; Trout, J.M. Cryptosporidium ryanae n. sp. (Apicomplexa: Cryptosporidiidae) in cattle (Bos Taurus). Vet. Parasitol. 2008, 156, 191-198. [CrossRef]

25. Åberg, M.; Emanuelson, U.; Troell, K.; Björkman, C. Infection dynamics of Cryptosporidium bovis and Cryptosporidium ryanae in a Swedish dairy herd. Vet. Parasitol. 2019, 276S, 100010. [CrossRef]

26. Izzo, M.M.; Kirkland, P.D.; Mohler, V.L.; Perkins, N.R.; Gunn, A.A.; House, J.K. Prevalence of major enteric pathogens in Australian dairy calves with diarrhoea. Aust. Vet. J. 2011, 89, 167-173. [CrossRef]

27. Kváč, M.; Kouba, M.; Vítovec, J. Age-related and housing-dependence of Cryptosporidium infection of calves from dairy and beef herds in South Bohemia, Czech Republic. Vet. Parasitol. 2006, 137, 202-209. [CrossRef]

28. Ryan, U.; Zahedi, A.; Paparini, A. Cryptosporidium in humans and animals-A one health approach to prophylaxis. Parasite Immunol. 2016, 38, 535-547. [CrossRef]

29. Nydam, D.V.; Wade, S.E.; Schaaf, S.L.; Mohammed, H.O. Number of Cryptosporidium parvum oocysts or Giardla spp. cysts shed by dairy calves after natural infection. Am. J. Vet. Res. 2001, 62, 1612-1615. [CrossRef]

30. Bushkin, G.G.; Motari, E.; Carpentieri, A. Evidence for a Structural Role for Acid-Fast Lipids in Oocyst Walls of Cryptosporidium, Toxoplasma, and Eimeria. MBio 2013, 4, 1-8. [CrossRef]

31. Koutsoumanis, K.; Allende, A.; Alvarez-Ordóñez, A.; Bolton, D.; Bover-Cid, S.; Chemaly, M.; Davies, R.; De Cesare, A.; Herman, L.; Hilbert, F.; et al. Public health risks associated with food-borne parasites. EFSA J. 2018, 16, e05495. [CrossRef]

32. Robertson, L.J.; Campbell, A.T.; Smith, H.V. Survival of Cryptosporidium parvum Oocysts under Various Environmental Pressures. Appl. Environ. Microbiol. 1992, 58, 3494-3500. [CrossRef]

33. Xiao, L.; Feng, Y. Molecular epidemiologic tools for waterborne pathogens Cryptosporidium spp. and Giardia duodenalis. Food Waterborne Parasitol. 2017, 8-9, 14-32. [CrossRef]

34. Sulaiman, I.M.; Hira, P.R.; Zhou, L.; Al-Ali, F.M.; Al-Shelahi, F.A.; Shweiki, H.M.; Iqbal, J.; Khalid, N.; Xiao, L. Unique Endemicity of Cryptosporidiosis in Children in Kuwait. J. Clin. Microbiol. 2005, 43, 2805-2809. [CrossRef] [PubMed]

35. Chalmers, R.M.; Robinson, G.; Elwin, K.; Elson, R. Analysis of the Cryptosporidium spp. and gp60 subtypes linked to human outbreaks of cryptosporidiosis in England and Wales, 2009 to 2017. Parasites Vectors 2019, 12, 1-13. [CrossRef]

36. Follet, J.; Guyot, K.; Leruste, H.; Follet-Dumoulin, A.; Hammouma-Ghelboun, O.; Certad, G.; Dei-Cas, E.; Halama, P. Cryptosporidium infection in a veal calf cohort in France: Molecular characterization of species in a longitudinal study. Vet. Res. 2011, $42,116$. [CrossRef]

37. Mammeri, M.; Chevillot, A.; Chenafi, I.; Julien, C.; Vallée, I.; Polack, B.; Follet, J.; Adjou, K.T. Molecular characterization of Cryptosporidium isolates from diarrheal dairy calves in France. Vet. Parasitol. Reg. Stud. Rep. 2019, 18, 100323. [CrossRef]

38. Ngouanesavanh, T.; Guyot, K.; Certad, G.; Fichoux, Y.L.; Chartier, C.; Verdier, R.I.; Cailliez, J.C.; Camus, D.; Dei-Cas, E.; Bañuls, A.L. Cryptosporidium Population Genetics: Evidence of Clonality in Isolates from France and Haiti. J. Eukaryot. Microbiol. 2006, 53 (Suppl. 1), 33-36. [CrossRef] [PubMed]

39. Rieux, A.; Chartier, C.; Pors, I.; Paraud, C. Dynamics of excretion and molecular characterization of Cryptosporidium isolates in pre-weaned French beef calves. Vet. Parasitol. 2013, 195, 169-172. [CrossRef] [PubMed]

40. Rieux, A.; Chartier, C.; Pors, I.; Delafosse, A.; Paraud, C. Molecular characterization of Cryptosporidium isolates from high-excreting young dairy calves in dairy cattle herds in Western France. Parasitol. Res. 2013, 112, 3423-3431. [CrossRef]

41. Rieux, A.; Paraud, C.; Pors, I.; Chartier, C. Molecular characterization of Cryptosporidium isolates from beef calves under one month of age over three successive years in one herd in western France. Vet. Parasitol. 2014, 202, 171-179. [CrossRef] [PubMed]

42. Rieux, A.; Paraud, C.; Pors, I.; Chartier, C. Molecular characterization of Cryptosporidium isolates from pre-weaned calves in western France in relation to age. Vet. Parasitol. 2013, 197, 7-12. [CrossRef] [PubMed]

43. Geurden, T.; Berkvens, D.; Martens, C.; Casaert, S.; Vercruysse, J.; Claerebout, E. Molecular epidemiology with subtype analysis of Cryptosporidium in calves in Belgium. Parasitology 2007, 134, 1981-1987. [CrossRef] [PubMed] 
44. Wielinga, P.R.; de Vries, A.; van der Goot, T.H.; Mank, T.; Mars, M.H.; Kortbeek, L.M.; van der Giessen, J.W.B. Molecular epidemiology of Cryptosporidium in humans and cattle in The Netherlands. Int. J. Parasitol. 2008, 38, 809-817. [CrossRef]

45. Ziegler, P.E.; Santucci, F.; Lindergard, G.; Nydam, D.V.; Wade, S.E.; Schaaf, S.L.; Chang, Y.-F.; Mohammed, H.O. Evaluation of polymerase chain reaction diagnosis of Cryptosporidium spp. in dairy cattle and wildlife. Vet. Ther. 2007, 8, 148-159. [PubMed]

46. Alves, M.; Xiao, L.; Sulaiman, I.; Lal, A.A.; Matos, O.; Antunes, F. Subgenotype Analysis of Cryptosporidium Isolates from Humans, Cattle, and Zoo Ruminants in Portugal. J. Clin. Microbiol. 2003, 41, 2744-2747. [CrossRef]

47. Guindon, S.; Gascuel, O. A Simple, Fast, and Accurate Algorithm to Estimate Large Phylogenies by Maximum Likelihood. Syst. Biol. 2003, 52, 696-704. [CrossRef]

48. Tamura, K.; Peterson, D.; Peterson, N.; Stecher, G.; Nei, M.; Kumar, S. MEGA5: Molecular Evolutionary Genetics Analysis Using Maximum Likelihood, Evolutionary Distance, and Maximum Parsimony Methods. Mol. Biol. Evol. 2011, 28, $2731-2739$. [CrossRef]

49. Tamura, K. Estimation of the Number of Nucleotide Substitutions When There Are Strong Transition-Transversion and G+CContent Biases. Mol. Biol. Evol. 1992, 9, 678-687. [CrossRef]

50. Santoro, A.; Dorbek-Kolin, E.; Jeremejeva, J.; Tummeleht, L.; Orro, T.; Jokelainen, P.; Lassen, B. Molecular epidemiology of Cryptosporidium spp. in calves in Estonia: High prevalence of Cryptosporidium parvum shedding and 10 subtypes identified. Parasitology 2019, 146, 261-267. [CrossRef]

51. Díaz, P.; Navarro, E.; Remesar, S.; García-Dios, D.; Martínez-Calabuig, N.; Prieto, A.; López-Lorenzo, G.; López, C.M.; Panadero, R.; Fernández, G.; et al. The Age-Related Cryptosporidium Species Distribution in Asymptomatic Cattle from North-Western Spain. Animals 2021, 11, 256. [CrossRef]

52. Kváč, M.; Hromadová, N.; Květoňová, D.; Rost, M.; Sak, B. Molecular characterization of Cryptosporidium spp. in pre-weaned dairy calves in the Czech Republic: Absence of C. ryanae and management-associated distribution of C. andersoni, C. bovis and C. parvum subtypes. Vet. Parasitol. 2011, 177, 378-382. [CrossRef]

53. Ondráčková, Z.; Kváč, M.; Sak, B.; Květoňová, D.; Rost, M. Prevalence and molecular characterization of Cryptosporidium spp. in dairy cattle in South Bohemia, the Czech Republic. Vet. Parasitol. 2009, 165, 141-144. [CrossRef]

54. Díaz, P.; Varcasia, A.; Pipia, A.P.; Tamponi, C.; Sanna, G.; Prieto, A.; Ruiu, A.; Spissu, P.; Díez-Baños, P.; Morrondo, P.; et al. Molecular characterisation and risk factor analysis of Cryptosporidium spp. in calves from Italy. Parasitol. Res. 2018, 117, 3081-3090. [CrossRef]

55. Holzhausen, I.; Lendner, M.; Göhring, F.; Steinhöfel, I.; Daugschies, A. Distribution of Cryptosporidium parvum gp60 subtypes in calf herds of Saxony, Germany. Parasitol. Res. 2019, 118, 1549-1558. [CrossRef]

56. Delafosse, A.; Chartier, C.; Dupuy, M.C.; Dumoulin, M.; Pors, I.; Paraud, C. Cryptosporidium parvum infection and asociated risk factors in dairy calves in western France. Prev. Vet. Med. 2015, 118, 406-412. [CrossRef] [PubMed]

57. Lichtmannsperger, K.; Hinney, B.; Joachim, A.; Wittek, T. Molecular characterization of Giardia intestinalis and Cryptosporidium parvum from calves with diarrhoea in Austria and evaluation of point-of-care tests. Comp. Immunol. Microbiol. Infect. Dis. 2019, 66, 101333. [CrossRef] [PubMed]

58. Thomson, S.; Innes, E.A.; Jonsson, N.N.; Katzer, F. Shedding of Cryptosporidium in calves and dams: Evidence of re-infection and shedding of different gp60 subtypes. Parasitology 2019, 146, 1404-1413. [CrossRef]

59. Feng, Y.; Ortega, Y.; He, G.; Das, P.; Xu, M.; Zhang, X.; Fayer, R.; Gatei, W.; Cama, V.; Xiao, L. Wide geographic distribution of Cryptosporidium bovis and the deer-like genotype in bovines. Vet. Parasitol. 2007, 144, 1-9. [CrossRef]

60. Huetink, R.E.C.; Van der Giessen, J.W.B.; Noordhuizen, J.P.T.M.; Ploeger, H.W. Epidemiology of Cryptosporidium spp. and Giardia duodenalis on a dairy farm. Vet. Parasitol. 2001, 102, 53-67. [CrossRef]

61. Khan, S.M.; Debnath, C.; Pramanik, A.K.; Xiao, L.; Nozaki, T.; Ganguly, S. Molecular characterization and assessment of zoonotic transmission of Cryptosporidium from dairy cattle in West Bengal, India. Vet. Parasitol. 2010, 171, 41-47. [CrossRef]

62. Maddox-Hyttel, C.; Langkjær, R.B.; Enemark, H.L.; Vigre, H. Cryptosporidium and Giardia in different age groups of Danish cattle and pigs-Occurrence and management associated risk factors. Vet. Parasitol. 2006, 141, 48-59. [CrossRef] [PubMed]

63. Maikai, B.V.; Umoh, J.U.; Kwaga, J.K.P.; Lawal, I.A.; Maikai, V.A.; Cama, V.; Xiao, L. Molecular characterization of Cryptosporidium spp. in native breeds of cattle in Kaduna State, Nigeria. Vet. Parasitol. 2011, 178, 241-245. [CrossRef] [PubMed]

64. Singh, B.B.; Sharma, R.; Kumar, H.; Banga, H.S.; Aulakh, R.S.; Gill, J.P.S.; Sharma, J.K. Prevalence of Cryptosporidium parvum infection in Punjab (India) and its association with diarrhea in neonatal dairy calves. Vet. Parasitol. 2006, 140, 162-165. [CrossRef] [PubMed]

65. Kváč, M.; Vitovec, J. Prevalence and pathogenicity of Cryptosporidium andersoni in one herd of beef cattle. J. Vet. Med. Ser. B 2003, 50, 451-457. [CrossRef]

66. Wells, B.; Shaw, H.; Hotchkiss, E.; Gilray, J.; Ayton, R.; Green, J.; Katzer, F.; Wells, A.; Innes, E. Prevalence, species identification and genotyping Cryptosporidium from livestock and deer in a catchment in the Cairngorms with a history of a contaminated public water supply. Parasites Vectors 2015, 8, 1-13. [CrossRef]

67. Soba, B.; Logar, J. Genetic classification of Cryptosporidium isolates from humans and calves in Slovenia. Parasitology 2008, 135, 1263-1270. [CrossRef]

68. Ayinmode, A.B.; Olakunle, F.B.; Xiao, L. Molecular characterization of Cryptosporidium spp. in native calves in Nigeria. Parasitol. Res. 2010, 107, 1019-1021. [CrossRef] 
69. Björkman, C.; Lindström, L.; Oweson, C.; Ahola, H.; Troell, K.; Axén, C. Cryptosporidium infections in suckler herd beef calves. Parasitology 2015, 142, 1108-1114. [CrossRef]

70. Budu-Amoako, E.; Greenwood, S.J.; Dixon, B.R.; Barkema, H.W.; McClure, J.T. Giardia and Cryptosporidium on Dairy Farms and the Role these Farms May Play in Contaminating Water Sources in Prince Edward Island, Canada. J. Vet. Intern. Med. 2012, 26, 668-673. [CrossRef]

71. Fan, Y.; Wang, T.; Koehler, A.V.; Hu, M.; Gasser, R.B. Molecular investigation of Cryptosporidium and Giardia in pre- and post-weaned calves in Hubei Province, China. Parasites Vectors 2017, 10, 3-9. [CrossRef] [PubMed]

72. Ma, J.; Li, P.; Zhao, X.; Xu, H.; Wu, W.; Wang, Y.; Guo, Y.; Wang, L.; Feng, Y.; Xiao, L. Occurrence and molecular characterization of Cryptosporidium spp. and Enterocytozoon bieneusi in dairy cattle, beef cattle and water buffaloes in China. Vet. Parasitol. 2015, 207, 220-227. [CrossRef] [PubMed]

73. Ng, J.; Yang, R.; McCarthy, S.; Gordon, C.; Hijjawi, N.; Ryan, U. Molecular characterization of Cryptosporidium and Giardia in pre-weaned calves in Western Australia and New South Wales. Vet. Parasitol. 2011, 176, 145-150. [CrossRef] [PubMed]

74. Silverlås, C.; Näslund, K.; Björkman, C.; Mattsson, J.G. Molecular characterisation of Cryptosporidium isolates from Swedish dairy cattle in relation to age, diarrhoea and region. Vet. Parasitol. 2010, 169, 289-295. [CrossRef]

75. Silverlås, C.; Blanco-Penedo, I. Cryptosporidium spp. in calves and cows from organic and conventional dairy herds. Epidemiol. Infect. 2013, 141, 529-539. [CrossRef]

76. Wang, R.; Wang, H.; Sun, Y.; Zhang, L.; Jian, F.; Qi, M.; Ning, C.; Xiao, L. Characteristics of Cryptosporidium Transmission in Preweaned Dairy Cattle in Henan, China. J. Clin. Microbiol. 2011, 49, 1077-1082. [CrossRef]

77. Zhang, X.X.; Tan, Q.D.; Zhou, D.H.; Ni, X.T.; Liu, G.X.; Yang, Y.C.; Zhu, X.Q. Prevalence and molecular characterization of Cryptosporidium spp. in dairy cattle, northwest China. Parasitol. Res. 2015, 114, 2781-2787. [CrossRef]

78. Santín, M. Clinical and subclinical infections with Cryptosporidium in animals. N. Z. Vet. J. 2013, 61, 1-10. [CrossRef]

79. Fayer, R.; Santín, M. Cryptosporidium xiaoi n. sp. (Apicomplexa: Cryptosporidiidae) in sheep (Ovis aries). Vet. Parasitol. 2009, 164, 192-200. [CrossRef]

80. Hijjawi, N.; Mukbel, R.; Yang, R.; Ryan, U. Genetic characterization of Cryptosporidium in animal and human isolates from Jordan. Vet. Parasitol. 2016, 228, 116-120. [CrossRef]

81. Gong, C.; Cao, X.F.; Deng, L.; Li, W.; Huang, X.M.; Lan, J.C.; Xiao, Q.C.; Zhong, Z.J.; Feng, F.; Zhang, Y.; et al. Epidemiology of Cryptosporidium infection in cattle in China: A review. Parasite 2017, 24, 1-8. [CrossRef] [PubMed]

82. Mirhashemi, M.E.; Zintl, A.; Grant, T.; Lucy, F.; Mulcahy, G.; De Waal, T. Molecular epidemiology of Cryptosporidium species in livestock in Ireland. Vet. Parasitol. 2016, 216, 18-22. [CrossRef] [PubMed]

83. Reed, C.; Sturbaum, G.D.; Hoover, P.J.; Sterling, C.R. Cryptosporidium parvum Mixed Genotypes Detected by PCR-Restriction Fragment Length Polymorphism Analysis. Appl. Environ. Microbiol. 2002, 68, 427-429. [CrossRef]

84. Tanriverdi, S.; Arslan, M.Ö.; Akiyoshi, D.E.; Tzipori, S.; Widmer, G. Identification of genotypically mixed Cryptosporidium parvum populations in humans and calves. Mol. Biochem. Parasitol. 2003, 130, 13-22. [CrossRef]

85. Hadfield, S.J.; Robinson, G.; Elwin, K.; Chalmers, R.M. Detection and Differentiation of Cryptosporidium spp. in Human Clinical Samples by Use of Real-Time PCR. J. Clin. Microbiol. 2011, 49, 918-924. [CrossRef]

86. Fayer, R.; Santín, M.; Dargatz, D. Species of Cryptosporidium detected in weaned cattle on cow-calf operations in the United States. Vet. Parasitol. 2010, 170, 187-192. [CrossRef]

87. Stensvold, C.R.; Ethelberg, S.; Hansen, L.; Sahar, S.; Voldstedlund, M.; Kemp, M.; Hartmeyer, G.N.; Otte, E.; Engsbro, A.L.; Nielsen, H.V.; et al. Cryptosporidium infections in Denmark, 2010-2014. Dan. Med. J. 2015, 62, 3-6.

88. Alves, M.; Xiao, L.; Antunes, F.; Matos, O. Distribution of Cryptosporidium subtypes in humans and domestic and wild ruminants in Portugal. Parasitol. Res. 2006, 99, 287-292. [CrossRef]

89. Aita, J.; Ichikawa-Seki, M.; Kinami, A.; Yaita, S.; Kumagai, Y.; Nishikawa, Y.; Itagaki, T. Molecular characterization of Cryptosporidium parvum detected in Japanese black and Holstein calves in Iwate Prefecture and Tanegashima Island, Kagoshima Prefecture, Japan. J. Vet. Med. Sci. 2015, 77, 997-999. [CrossRef]

90. Caffarena, R.D.; Meireles, M.V.; Carrasco-Letelier, L.; Picasso-Risso, C.; Santana, B.N.; Riet-Correa, F.; Giannitti, F. Dairy Calves in Uruguay Are Reservoirs of Zoonotic Subtypes of Cryptosporidium parvum and Pose a Potential Risk of Surface Water Contamination. Front. Vet. Sci. 2020, 7, 1-15. [CrossRef]

91. Garcia-R, J.C.; Pita, A.B.; Velathanthiri, N.; French, N.P.; Hayman, D.T.S. Species and genotypes causing human cryptosporidiosis in New Zealand. Parasitol. Res. 2020, 119, 2317-2326. [CrossRef] [PubMed]

92. Guy, R.A.; Yanta, C.A.; Muchaal, P.K.; Rankin, M.A.; Thivierge, K.; Lau, R.; Boggild, A.K. Molecular characterization of Cryptosporidium isolates from humans in Ontario, Canada. Parasites Vectors 2021, 14, 1-14. [CrossRef]

93. Ma, D.W.; Lee, M.R.; Hong, S.H.; Cho, S.H.; Lee, S.E. Molecular Prevalence and Genotypes of Cryptosporidium parvum and Giardia duodenalis in Patients with Acute Diarrhea in Korea, 2013-2016. Korean J. Parasitol. 2019, 57, 531-536. [CrossRef]

94. Quilez, J.; Torres, E.; Chalmers, R.M.; Robinson, G.; Del Cacho, E.; Sanchez-Acedo, C. Cryptosporidium species and subtype analysis from dairy calves in Spain. Parasitology 2008, 135, 1613-1620. [CrossRef] [PubMed]

95. García-Presedo, I.; Pedraza-Díaz, S.; González-Warleta, M.; Mezo, M.; Gómez-Bautista, M.; Ortega-Mora, L.M.; Castro-Hermida, J.A. Presence of Cryptosporidium scrofarum, C. suis and C. parvum subtypes IIaA16G2R1 and IIaA13G1R1 in Eurasian wild boars (Sus scrofa). Vet. Parasitol. 2013, 196, 497-502. [CrossRef] [PubMed] 
96. Hijjawi, N.; Zahedi, A.; Kazaleh, M.; Ryan, U. Prevalence of Cryptosporidium species and subtypes in paediatric oncology and non-oncology patients with diarrhoea in Jordan. Infect. Genet. Evol. 2017, 55, 127-130. [CrossRef]

97. Hutter, J.A.; Dion, R.; Irace-Cima, A.; Fiset, M.; Guy, R.; Dixon, B.; Aguilar, J.L.; Trépanier, J.; Thivierge, K. Cryptosporidium spp.: Human incidence, molecular characterization and associated exposures in Québec, Canada (2016-2017). PLoS ONE 2020, 15, 1-13. [CrossRef]

98. Benhouda, D.; Hakem, A.; Sannella, A.R.; Benhouda, A.; Cacciò, S.M. First molecular investigation of Cryptosporidium spp. in young calves in Algeria. Parasite 2017, 24, 1-6. [CrossRef]

99. Taylan-Ozkan, A.; Yasa-Duru, S.; Usluca, S.; Lysen, C.; Ye, J.; Roellig, D.M.; Feng, Y.; Xiao, L. Cryptosporidium species and Cryptosporidium parvum subtypes in dairy calves and goat kids reared under traditional farming systems in Turkey. Exp. Parasitol. 2016, 170, 16-20. [CrossRef]

100. Trotz-Williams, L.A.; Martin, D.S.; Gatei, W.; Cama, V.; Peregrine, A.S.; Martin, S.W.; Nydam, D.V.; Jamieson, F.; Xiao, L. Genotype andsSubtype analyses of Cryptosporidium isolates from dairy calves and humans in Ontario. Parasitol. Res. 2006, 99, 346-352. [CrossRef]

101. Iqbal, A.; Lim, Y.A.L.; Surin, J.; Sim, B.L.H. High Diversity of Cryptosporidium Subgenotypes Identified in Malaysian HIV/AIDS Individuals Targeting gp60 Gene. PLoS ONE 2012, 7, e31139. [CrossRef] [PubMed]

102. Kaupke, A.; Rzeżutka, A. Emergence of novel subtypes of Cryptosporidium parrum in calves in Poland. Parasitol. Res. 2015, 114, 4709-4716. [CrossRef] [PubMed]

103. Hatalová, E.; Valenčáková, A.; Luptáková, L.; Špalková, M.; Kalinová, J.; Halánová, M.; Bednárová, V.; Gabzdilová, J.; Dedinská, K.; Ondriska, F.; et al. The first report of animal genotypes of Cryptosporidium parvum in immunosuppressed and immunocompetent humans in Slovakia. Transbound. Emerg. Dis. 2019, 66, 243-249. [CrossRef]

104. Certad, G.; Dupouy-Camet, J.; Gantois, N.; Hammouma-Ghelboun, O.; Pottier, M.; Guyot, K.; Benamrouz, S.; Osman, M.; Delaire, B.; Creusy, C.; et al. Identification of Cryptosporidium Species in Fish from Lake Geneva (Lac Léman) in France. PLoS ONE 2015, 10, 1-13. [CrossRef]

105. Certad, G.; Follet, J.; Gantois, N.; Hammouma-Ghelboun, O.; Guyot, K.; Benamrouz-Vanneste, S.; Fréalle, E.; Seesao, Y.; Delaire, B.; Creusy, C.; et al. Prevalence, Molecular Identification, and Risk Factors for Cryptosporidium Infection in Edible Marine Fish: A Survey across Sea Areas Surrounding France. Front. Microbiol. 2019, 10, 1-15. [CrossRef]

106. Thompson, H.P.; Dooley, J.S.G.; Kenny, J.; McCoy, M.; Lowery, C.J.; Moore, J.E.; Xiao, L. Genotypes and subtypes of Cryptosporidium spp. in neonatal calves in Northern Ireland. Parasitol. Res. 2007, 100, 619-624. [CrossRef]

107. Danišová, O.; Valenčáková, A.; Petrincová, A. Detection and identification of six Cryptospordium species in livestock in Slovakia by amplification of SSU and GP60 Genes with the Use of PCR Analysis. Ann. Agric. Environ. Med. 2016, 23, 254-258. [CrossRef]

108. Kiani, H.; Haghighi, A.; Seyyedtabaei, S.J.; Azargashsb, E.; Zebardast, N.; Taghipour, N.; Rostami, A.; Xiao, L. Prevalence, Clinical Manifestations and Genotyping of Cryptosporidium spp. in Patients with Gastrointestinal Illnesses in Western Iran. Iran. J. Parasitol. 2017, 12, 169-176.

109. Imre, K.; Lobo, L.M.; Matos, O.; Popescu, C.; Genchi, C.; Dărăbuş, G. Molecular characterisation of Cryptosporidium isolates from pre-weaned calves in Romania: Is there an actual risk of zoonotic infections? Vet. Parasitol. 2011, 181, 321-324. [CrossRef] [PubMed]

110. Plutzer, J.; Karanis, P. Genotype and subtype analyses of Cryptosporidium isolates from cattle in Hungary. Vet. Parasitol. 2007, 146, 357-362. [CrossRef] [PubMed]

111. Broglia, A.; Reckinger, S.; Cacció, S.M.; Nöckler, K. Distribution of Cryptosporidium parvum subtypes in calves in Germany. Vet. Parasitol. 2008, 154, 8-13. [CrossRef] [PubMed]

112. Lassen, B.; Ståhl, M.; Enemark, H.L. Cryptosporidiosis-An occupational risk and a disregarded disease in Estonia. Acta Vet. Scand. 2014, 56, 36. [CrossRef] [PubMed]

113. Kinross, P.; Beser, J.; Troell, K.; Silverlas, C.; Björkman, C.; Lebbad, M.; Winiecka-Krusnell, J.; Lindh, J.; Löfdahl, M. Cryptosporidium parvum infections in a cohort of veterinary students in Sweden. Epidemiol. Infect. 2015, 143, 2748-2756. [CrossRef]

114. Baptista, R.P.; Cooper, G.W.; Kissinger, J.C. Challenges for Cryptosporidium Population Studies. Genes 2021, 12, 894. [CrossRef]

115. Troell, K.; Hallström, B.; Divne, A.M.; Alsmark, C.; Arrighi, R.; Huss, M.; Beser, J.; Bertilsson, S. Cryptosporidium as a testbed for single cell genome characterization of unicellular eukaryotes. BMC Genom. 2016, 17, 1-12. [CrossRef] [PubMed]

116. Morris, A.; Robinson, G.; Swain, M.T.; Chalmers, R.M. Direct Sequencing of Cryptosporidium in Stool Samples for Public Health. Front. Public Health 2019, 7, 360. [CrossRef]

117. Grinberg, A.; Biggs, P.J.; Dukkipati, V.S.R.; George, T.T. Extensive intra-host genetic diversity uncovered in Cryptosporidium paroum using Next Generation Sequencing. Infect. Genet. Evol. 2013, 15, 18-24. [CrossRef]

118. Zahedi, A.; Gofton, A.W.; Jian, F.; Paparini, A.; Oskam, C.; Ball, A.; Robertson, I.; Ryan, U. Next Generation Sequencing uncovers within-host differences in the genetic diversity of Cryptosporidium gp60 subtypes. Int. J. Parasitol. 2017, 47, 601-607. [CrossRef] 